\title{
Inflammatory processes in cardiovascular disease: a route to targeted therapies
}

\author{
Neil Ruparelia ${ }^{1}$, Joshua T. Chai ${ }^{1,2}$, Edward A. Fisher ${ }^{1,3}$, and Robin P. Choudhury ${ }^{1,2}$ \\ ${ }^{1}$ Division of Cardiovascular Medicine, Radcliffe Department of Medicine, John Radcliffe Hospital, \\ University of Oxford, Headley Way, Oxford, OX3 9DU, UK \\ ${ }^{2}$ Acute Vascular Imaging Centre, University of Oxford. John Radcliffe Hospital, University of \\ Oxford, Headley Way, Oxford, OX3 9DU, UK \\ ${ }^{3}$ The Center for the Prevention of Cardiovascular Disease and the Division of Cardiology, \\ Department of Medicine, New York University School of Medicine, New York, NY 10016, USA
}

\begin{abstract}
Inflammatory processes are firmly established as central to the development and complications of cardiovascular diseases. Elevated levels of inflammatory markers have been shown to be predictive of future cardiovascular events. The specific targeting of these processes in experimental models has been shown to attenuate myocardial and arterial injury, reduce disease progression, and promote healing. However, the translation of these observations and the demonstration of clear efficacy in clinical practice have been disappointing. A major limitation might be that tools currently used to measure 'inflammation' are insufficiently precise and do not provide information about disease site, activity, or discriminate between functionally important activation pathways. The challenge, therefore, is to make measures of inflammation that are more meaningful, and which can guide specific targeted therapies. In this Review, we consider the roles of inflammatory processes in the related pathologies of atherosclerosis and acute myocardial infarction (AMI), by providing an evaluation of the known and emerging inflammatory pathways. We highlight contemporary techniques to characterize and quantify inflammation, and consider how they might be used to guide specific treatments. Finally, we discuss emerging opportunities in the field, including current limitations and challenges that are the focus of ongoing study.
\end{abstract}

Inflammation and its failure to resolve are firmly established as central to the development and complications of several cardiovascular diseases ${ }^{1-3}$. Elevated levels of markers of inflammation, such as C-reactive protein (CRP) and serum amyloid A (SAA), have been shown to be predictive of future cardiovascular events across a range of clinical settings ${ }^{4-6}$. The role of the innate immune system in the pathogenesis of cardiovascular diseases has been an area of particular focus, with the appreciation that targeting innate immune function

Correspondence to R.P.C.: robin.choudhury@ cardiov.ox.ac.uk.

Author contributions

All the authors researched data for the article, discussed its contents, and wrote, reviewed, and edited the manuscript before submission.

Competing interests statement

The authors declare no competing interests. 
in experimental models can variously attenuate disease progression and injury, and promote healing ${ }^{7-10}$.

Processes of inflammation contribute to a broad range of cardiovascular diseases; however, in this Review, we consider the roles of inflammatory processes in the related pathologies of atherosclerosis and acute myocardial infarction (AMI), by providing an evaluation of known and emerging inflammatory pathways that are thought to be central to their pathogenesis, and the consequences of their activation. We highlight contemporary techniques to characterize and quantify inflammation, and consider how these might be used to guide specific treatments. Finally, we discuss emerging opportunities in the field, including current limitations and challenges that are the focus of ongoing study.

As interest in this field has expanded, one of the main challenges has been the use of the term 'inflammation' to cover a wide variety of processes and observations, some of which are very poorly defined. For instance, 'inflammation' can include observation of nonspecific changes in acute-phase proteins (such as CRP and SAA) that are produced in the liver, remotely from the site of pathology, but also encompasses a nuanced understanding of local molecular and cellular processes in the heart or vessel wall that are intimately involved in disease causation. Therefore, our approach is to try to identify and elaborate on mechanistically important inflammatory processes, to link these to clinically relevant biomarkers, and to focus on pathways that are therapeutically tractable.

A major limitation has been that the biomarkers that are currently used to gauge inflammation are crude and nonspecific (for example, CRP). They reflect the downstream consequences of inflammatory activity, but do not provide information relating to the site(s) of activation and cannot be used to discriminate functionally important activation pathways. The challenge, therefore, is to make measures of inflammation that are meaningful to the pathology of interest and which can guide specific, targeted therapies.

\section{Inflammation and cardiovascular disease}

Following the first observations of the role of inflammatory processes in cardiovascular disease $^{3}$, our understanding of these complex processes has greatly expanded. Their complexity and central roles in the pathogenesis of cardiovascular disease are now at least partially appreciated. Indeed, the term 'inflammation' is now used to describe a broad range of processes including those at the site of disease, in the blood, at remote sites, and also as downstream sequelae of disease - with each representing very different biology. Importantly for clinical purposes, techniques have not evolved to enable the reliable, specific, and accurate characterization of these processes.

\section{Acute myocardial infarction}

\section{Pathogenesis}

AMI most commonly results from the acute rupture of a coronary atherosclerotic plaque resulting in the rapid formation of thrombus in the infarct-related epicardial artery and loss of blood flow distal to the site of occlusion ${ }^{11}$. Other causes include plaque erosions and 
calcific nodules ${ }^{12}$. Myocardial ischaemia results in the activation of a well-orchestrated immune response, both locally at the site of injury, but also in the circulating blood and at remote sites (FIG. 1). These processes are important as both mediators of injury and subsequently in repair and recovery ${ }^{2}$. Elevated plasma levels of nonspecific indicators of inflammation (such as high-sensitivity CRP and IL-6) have indicated that their continued upregulation is associated with worse outcomes ${ }^{13,14}$.

Inflammatory pathways locally in the myocardium-Myocardial ischaemia leads to cardiomyocyte injury and, if prolonged, death, with release of their intracellular contents and changes to the extracellular matrix. This process results in endogenous signals that trigger a cytokine 'burst', activation of platelets that mediate leukocyte activation and their tissue infiltration ${ }^{15}$, and the rapid recruitment of neutrophils to the myocardium, which following degranulation cause direct injury to endothelial cells and production of reactive oxidation species (ROS), proteases, and cytokines ${ }^{16}$. In response, endothelial cells increase expression of leukocyte and platelet adhesion molecules and compromise of intercellular tight junctions facilitates the binding and transmigration of circulating monocytes ${ }^{17}$ that coincides with a reduction of in-situ neutrophils secondary to a combination of local cell death and egress from the site ${ }^{18,19}$.

These endogenous signals are often referred to as 'danger associated molecular patterns' (DAMPs) and include heat-shock proteins ${ }^{20}$, high-mobility group protein $\mathrm{B}^{21}$, lowmolecular hyaluronic $\operatorname{acid}^{22}$, and fibronectin fragments ${ }^{23}$, which can all activate innate immune pathways, including Toll-like receptors (TLRs) ${ }^{24}$, nucleotide-binding domain leucine-rich repeat containing receptors (NLRs), the complement cascade, and reactive oxygen species (ROS) production.

Of the TLRs, cardiomyocyte expression of TLR4, also a major feature of activated macrophages, is substantially increased in response to DAMPs ${ }^{25}$. TLR4 deficiency is associated with decreased infarct size, a reduction in systemic inflammation ${ }^{26}$, and improved left ventricular remodelling ${ }^{27}$ in experimental models. In patients after AMI, TLR4 activation in monocytes (the precursors of macrophages) is associated with the development of heart failure ${ }^{28}$. Conversely, TLR2 deficiency is associated with reduced myocardial fibrosis after AMI and improved left ventricular remodelling ${ }^{29}$. TLR4, therefore, seems to be an important component in the initial inflammatory response, and TLR2 central to repair and left ventricular remodelling ${ }^{30}$.

Among the various NLRs, the NLRP3 (NACT, LRR and PYD domains-containing protein 3 inflammasome complex has been identified as an important mediator of injury after myocardial ischaemia and includes NLRP3, apoptosis-associated speck-like protein containing a CARD, and the cysteine protease caspase $1^{31}$. The activated NLRP3 inflammasome binds and activates caspase 1 that converts interleukin- $1 \beta$ (IL-1 $\beta$ ) to its active form, and is central to the activation of other cytokines ${ }^{32}$. The complement system consists of cell membrane (and plasma) proteins, many of which circulate as pro-enzymes. Complement activation has an important role in mediating neutrophil and monocyte recruitment acutely to the injured myocardium by the downstream complement effectors $\mathrm{C} 3 \mathrm{a}$ and C5a, and the release of monocyte chemotactic protein 1 (also known as C-C motif 
chemokine 2; CCL2 by vascular smooth muscle cells, microvascular endothelial cells, and macrophages ${ }^{33-36}$.

ROS are also released immediately by ischaemic cardiomyocytes after AMI, and induce leukocyte chemokine upregulation ${ }^{37}$, resulting in an increased capacity of endothelial intercellular adhesion molecule 1 (ICAM1) ligands to bind to neutrophils ${ }^{38}$, complement activation $^{39}$, and the recruitment of additional leukocyte subpopulations that subsequently become activated. Cytokines also contribute to the pathophysiology of AMI, with tumour necrosis factor (TNF), IL-1 $\beta$, and IL-6 all having central roles. For example, TNF can promote the release of other proinflammatory chemokines and adhesion molecule synthesis in the infarcted myocardium, augmenting further leukocyte infiltration ${ }^{40}$. TNF has interestingly also been shown to be protective of apoptosis, though its net actions are thought to be deleterious in $\mathrm{AMI}^{41}$. IL-1 $\beta$ similarly mediates injurious processes and leukocyte infiltration $^{42}$. IL-6 is also upregulated after myocardial ischaemia and modulates its actions through activation of the JAK/STAT (Janus tyrosine kinase/signal transducer and activator of transcription) cascade ${ }^{43,44}$.

Activation of remote inflammatory pathways and processes-Initially, 'classical' inflammatory monocyte subsets are mobilized and recruited from the blood, but in experimental models, there follows a rapid and massive mobilization of monocytes from the spleen and bone marrow ${ }^{45}$, which is also likely to occur in humans ${ }^{46}$. The precise stimuli to effect remote monocyte mobilization are incompletely understood, but include $\beta_{3}$ adrenoceptor activation in the bone marrow $^{47}$ and local action of CCL2 via C-C chemokine receptor type $2(\mathrm{CCR} 2)^{17}$.

After recruitment to the injured myocardium, blood-derived macrophages in synergy with resident macrophages initially function to scavenge necrotic debris and are active in local proteolysis and phagocytosis 48 . This stage is followed by a second phase consisting of the accumulation of nonclassical macrophages promoting reparative processes, such as angiogenesis and extracellular matrix deposition ${ }^{17,49}$. The precise roles of the various cardiac macrophage subsets either in the steady state or after AMI remain largely unknown. Additionally, the macrophages also communicate with other cell types (such as B cells, neutrophils, and mast cells) to exert further local and remote actions in both tissue injury and repair $^{50,51}$. Leukocyte numbers then return to baseline within 2 weeks in both the heart and blood.

Role of adaptive immunity-In contrast to the innate immune system (consisting primarily of monocyte-derived cells), which provides immediate defence against tissue injury by responding to general factors without pre-exposure, the adaptive immune system (that is, lymphocytes) provides the capacity to react to specific antigens after exposure, and to maintain memories of them.

In AMI, lymphocytes constitute a very small proportion of the infiltrating cell population ${ }^{52}$. However, the higher systemic frequency of activated T lymphocytes in patients with AMI compared with those with stable angina ${ }^{53,54}$ suggests that the adaptive immune system is also activated. In particular, $\mathrm{CD} 4{ }^{+} \mathrm{CD} 28^{\text {null }} \mathrm{T}$-effector cells are increased in the peripheral 
blood of patients after $\mathrm{AMI}^{55}$, and release proinflammatory cytokines (such as interferon- $\gamma$ ), activating monocytes and tissue macrophages, with the level of increase positively correlated with the risk of future acute coronary events ${ }^{56}$. Conversely, $\mathrm{CD} 4{ }^{+} \mathrm{CD} 25^{+}$regulatory $\mathrm{T}$ cells $\left(T_{R E G}\right)$ release anti-inflammatory cytokines, such as IL-10. After AMI, there seems to be an imbalance in T-cell subsets, with a reduction in $\mathrm{T}_{\mathrm{REG}}$ numbers ${ }^{57}$. This imbalance might indicate that, in these individuals, the counter-regulatory response to the activation of effector $\mathrm{T}$ cells is impaired. $\mathrm{T}$ lymphocytes have also been shown to have a role in recovery after AMI in experimental models, with the activation of $\mathrm{CD} 4^{+} \mathrm{T}$ cells required for optimal wound healing and remodelling of the left ventricle ${ }^{52}$.

Evidence of inflammation at remote sites-The activation of the immune system after AMI also results in general systemic inflammation, as evidenced by increased plasma levels of inflammatory cytokines, which are positively correlated with adverse outcomes ${ }^{5}$. Observational human studies have also demonstrated that plasma levels of TNF are strongly associated with the occurrence of reperfusion injury after recanalization of the infarct-related $\operatorname{artery}^{58}$, and with an increased risk of death ${ }^{59}$. Levels of TNF, IL-1, and IL-6 are significantly elevated in patients with AMI complicated by cardiogenic shock when compared with patients with uncomplicated $\mathrm{AMI}^{60}$. The extent to which systemic levels of cytokines give meaningful insight into the state of local inflammatory pathways is uncertain, but the complexities of the local processes of inflammation in injury and repair seem to argue against a predictive approach dependent on a single circulating reporter biomarker.

\section{Targeting of biological processes}

The ability to target therapeutically these inflammatory central biological processes could potentially attenuate myocardial injury, augment repair and recovery, and reduce the risk of future events. For example, in experimental myocardial infarction, the targeting of inflammatory 'classical' monocytes to reduce the total number of monocytes recruited to infarcted, inflamed myocardium by splenectomy or by the administration of angiotensinconverting-enzyme inhibitors has been shown to result in a reduction in infarct size and improved left ventricular function ${ }^{61}$. Similarly, targeting their recruitment with the administration of CCR2-siRNA delivered by nanoparticles also resulted in a reduction in the number of recruited monocytes, with a consequent reduction in infarction size and improved left ventricular function ${ }^{8,62}$. On the basis of these (and other) promising experimental data, a number of agents have been or are currently being investigated in clinical trials (TABLE 1).

To date, however, clinical efficacy has not been demonstrated with any agent. The reasons for this lack of success are likely to be multifactorial. One possible reason might be that the experimental model that has been used in initial therapeutic evaluation is not representative of human disease. Secondly, a common theme to each of these studies is that, in general, enrolment has been on the basis of the crude diagnosis of AMI, without attempts at stratification or 'mechanistic staging'. As discussed above, the underlying pathogenesis of AMI is a complex interaction between multiple biological processes. In combination with the historical ineffectiveness of general anti-inflammatory drugs in this setting, a 'one size fits all' approach might not be appropriate to determine efficacy, and a more-targeted approach to identify patients who would benefit from specific interventions is required. 
Molecular techniques-The quantification of a number of different blood components has commonly been used to measure 'inflammatory' processes and has included soluble adhesion molecules (such as ICAM1, P-selectin, and vascular cell adhesion molecule 1 [VCAM1]), cytokines (such as IL-1 $\beta$, IL-6, and TNF) ${ }^{63}, \mathrm{SAA}^{64}, \mathrm{CRP}^{65}$, and peripheral white cells ${ }^{66,67}$. With greater understanding of the underlying biology, it is increasingly apparent that these markers actually represent very different biological processes, can be 'upstream' or 'downstream' of the pathological process of interest, might not be specific, and provide little indication of activity, site, or status. Levels of high-sensitivity CRP, for example, have been observed to be acutely elevated after ischaemic events ${ }^{68}$ and, when chronically elevated, have been shown to be associated with an increased risk of future vascular events ${ }^{69,70}$. Mendelian randomization studies, however, have indicated that no causative relationship exists between single nucleotide polymorphisms associated with elevated CRP levels and coronary heart disease ${ }^{71}$, and the specific targeting of the molecule was not associated with benefit in preclinical studies ${ }^{72}$.

One approach to improve characterization of circulating immune cells after AMI has been to use flow cytometry-based techniques. This powerful approach has enabled more-precise phenotyping of leukocyte populations (such as identification of monocyte subsets) and considerable heterogeneity in both phenotype and function has been observed. Using monocytes as an example, flow cytometry can be used to phenotype the total cell population into subsets on the basis of the cell-surface expression of CD14 and CD16 ${ }^{73}$, with $\mathrm{CD} 14^{++} \mathrm{CD} 16^{-}$monocytes that express CCR2 thought to be 'inflammatory'. However, even with these more sophisticated phenotyping techniques, measuring circulating levels of individual soluble biomarkers or the identification of changes in crude counts of leukocyte subtypes is unlikely to provide sufficiently granular information to inform targeted drug selection.

To this end, transcriptomic analysis of circulating monocytes after AMI has identified patterns of gene expression that are conserved between mice and humans ${ }^{30}$. Although not yet formally tested, defined patterns of gene expression in downstream effector cells might plausibly give a more-precise insight into the activity of relevant pathways than measuring soluble biomarkers of uncertain origin and or site of action.

In AMI, circulating monocytes display patterns of gene expression in common with 'inflammation' and 'mitosis', with CD14, IL-1, and TLR2 identified as highly relevant components of the response using gene-set-enrichment techniques ${ }^{30,74}$. Analogous approaches have been used to validate preclinical models of disease, identify new therapeutic targets ${ }^{30}$ and, clinically, gene sets in circulating leukocytes have been used to diagnose cardiac transplantation rejection ${ }^{75}$. Such approaches also borrow from the field of oncology, where they have enabled the reclassification of many malignancies on the basis of molecular signatures that have different prognostic and therapeutic responses ${ }^{76}$. In breast cancer, microarray analysis of frozen breast tissue has been used to develop a 70-gene panel called Mammaprint, which can provide a prognostic measure of the likelihood of distant metastasis within 5 years of completing treatment ${ }^{77}$. Technological advances have enabled single-cell analysis to provide information about the heterogeneity of the human bone marrow cell population against which diseased states and response to drug treatment could 
be compared as a basis of mechanistic studies ${ }^{78}$. Complementing transcriptome profiling, proteomic studies have also been used to investigate changes in serum protein levels and, using this approach, haptoglobin has been identified a possible prognostic biomarker after AMI $^{79}$. Similarly, metabolomics ${ }^{80}$ and lipidomics ${ }^{81}$ methods, although in their infancy, can be also used to identify novel therapeutic targets, and possibly monitor disease activity. Future approaches might enable incorporation of complex, integrated datasets spanning multiple -omics domains and with much greater sampling frequency to allow higher resolution of temporal changes than is currently possible.

Extracellular vesicles have also gained interest as both a diagnostic tool and a potential therapeutic target. They have been shown to be important in cell-to-cell signalling, including in the context of inflammation. Extracellular vesicles carry a variety of cell-derived molecules including proteins ${ }^{82}$, mRNA, and microRNA ${ }^{83}$, and include exosomes (30-100 $\mathrm{nm}$ ), multivesicular bodies (also called ectosomes or microparticles: $100-1,000 \mathrm{~nm})^{84}$ and apoptotic bodies $(1-5 \mu \mathrm{m})^{85,86}$. Extracellular vesicles are continually produced by all cell types and, in the setting of AMI, those from endothelial cells and platelets have been shown to have roles in homeostasis of the cardiovascular system including coagulation ${ }^{87}$ and tissue repair $^{88}$. After AMI, levels of multivesicular bodies increase ${ }^{89}$ and are likely to exert their actions through mediating cell-to-cell signalling via transport of bioactive proteins between cells ${ }^{90}$ resulting in direct activation of target cells ${ }^{91,92}$. Several miRNAs found in extracellular vesicles might have roles in cardiovascular disease ${ }^{93}$, for example miR-150 released from monocytes that enhances cell migration ${ }^{94}$. Extracellular vesicles might, therefore, be a tool to predict future risk ${ }^{95}$, determine disease activity, be a therapeutic target, or provide templates for the engineering of vesicles that consist of a payload with a specific, targeted function.

Imaging techniques-Measuring blood biomarkers, in however sophisticated a way, cannot provide precise information on the distribution of pathology or accurately assess its anatomical extent. In combination with molecular tools, imaging modalities can be employed to determine disease activity and site. MRI is commonly used in the clinical setting and provides information about location and extent of acute myocardial injury, with quantification of myocardial oedema and also of irreversible injury with late gadolinium enhancement indicating myocardial scar.

The administration of ultra-small particle of iron oxide seems to improve specificity with which the location of infiltrating macrophages can be identified ${ }^{96,97}$. In experimental models of AMI, the application of ${ }^{18}$ fluorodeoxyglucose $\left({ }^{18} \mathrm{FDG}\right)$ PET in combination with MRI further improved localization of infiltration of metabolically active leukocytes in experimental models ${ }^{98}$, with cellular imaging studies supporting these conclusions ${ }^{99}$. Clinical studies have demonstrated similar findings, which provide the capacity to quantify metabolic activity in the myocardium after infarction ${ }^{100}$, monitor continued disease activity, and might also provide a prognostic marker of functional outcome ${ }^{101}$.

Further information that we have termed 'mechanistic staging' might be obtained from quantitative molecular imaging techniques that target important known processes, ideally on a mechanistic pathway that can be paired to a specific therapeutic agent or intervention. For 
example, quantitative molecular imaging has been described for VCAM1 and P-selectin using 'leukocyte-mimetic' particles to examine extent and distribution of endothelial activation ${ }^{102,103}$, which has also been applied to measure the 'imprint' of previous ischaemia ${ }^{104}$. An alternative approach has been to image proteases that are critical in the pathogenesis of disease and has been applied to preclinical models ${ }^{105}$ and humans after $\mathrm{AMI}^{100}$. Therefore, by utilizing a combination of molecular and imaging techniques, it might be possible not only to identify therapeutic targets, but also to identify patients with 'active' disease, localize sites of activity, and monitor response to therapy.

\section{Atherosclerosis}

\section{Pathogenesis}

Atherosclerosis is a chronic inflammatory process ${ }^{106}$. Immune cells are important mediators from the earliest fatty streaks to late-stage complex plaques. As knowledge of the immune processes in atherogenesis has expanded, opportunities for therapy through their manipulation or modification have become apparent. However, tools to determine disease severity and activity remain fairly crude.

Endothelial cells, lymphocytes, smooth muscle cells, monocytes, and macrophages are all involved in the pathogenesis of atherosclerosis from earliest foam cell formation through to development of advanced plaques (FIG. 2). ${ }^{107}$ Initial activation of the endothelium from disruptions to normal shear stress result in an increase in permeability to lipoproteins and upregulation of adhesion receptors ${ }^{108}$, and facilitate deposition of lipid from apolipoprotein $\mathrm{B}$ (apoB)-containing lipoproteins in the subendothelial space. Endothelial activation also promotes recruitment of circulating monocytes that originate from either the bone marrow ${ }^{109}$ or the spleen ${ }^{45}$. Monocyte adhesion depends on the upregulation of a number of cell-adhesion molecules on the luminal surface of the endothelium, ${ }^{110}$ notably, ICAM1, Pselectin, and VCAM1; followed by the expression of three major chemokine families, CCR2, CCR5, and CX3C chemokine receptor 1 (CX3CR1), that facilitate the transmigration process ${ }^{111,112}$. After recruited from the spleen and bone marrow ${ }^{113}$, monocytes can terminally differentiate into macrophages ${ }^{114}$, differentiate and locally proliferate into distinct functional phenotypes ${ }^{115}$, or directly influence the phenotype of in situ cells (for example, lesional macrophages) ${ }^{116}$. Lipids from retained apoB-containing lipoproteins are taken up by activated macrophages by a number of processes, including phagocytosis of aggregated $\mathrm{LDL}^{117}$, pinocytosis of $\mathrm{LDL}^{118}$, uptake of modified apoB-lipoproteins by scavenger receptors, and uptake by $\mathrm{CD} 36$. Ongoing lipid accumulation induces their transformation into macrophage-derived foam cells. As the foam cell population grows within lesions in the arterial wall, the rate of accumulation exceeds the rate of clearance ${ }^{119}$, and eventually the foam cells coalesce into a lipid-rich necrotic core.

A number of secreted cytokines are also implicated in the pathogenesis of atherogenesis. Cells of both the innate (macrophages) and adaptive ( $\mathrm{T}$ and $\mathrm{B}$ lymphocytes, dendritic cells) immune systems can modulate the local inflammatory milieu. Depending on their local environment, $\mathrm{T}$ lymphocytes can be stimulated to secrete proinflammatory $\mathrm{T}_{\mathrm{h}} 1$ cytokines such IL-1, IL-6, and TNF; or $\mathrm{T}_{\mathrm{h}} 2$ cytokines such as IL-4, IL-10, and IL-13, which promote resolution of inflammation. IL-1 and TNF signalling is primarily mediated by p38 mitogen- 
activated protein kinase (MAPK) / nuclear factor (NF)- $\mathrm{kB}$ pathways ${ }^{120}$. Conversely, activation of IL-6 signals via signal transducing protein gp130, which activates JAK1 and STAT 1 and $3^{121}$ resulting in the activation of endothelial cells and macrophages to produce adhesion molecules and chemokines ${ }^{122}$.

The physical properties within the plaque can also have an important role in the propagation of disease. Neovascularization in human plaques originating from the vasa vasorum is thought to contribute to intraplaque haemorrhage, which not only accelerates plaque expansion and inflammation, but also predicts future plaque rupture ${ }^{123,124}$. Angiogenesis is driven by vascular endothelial growth factor, which is a major downstream target of hypoxia inducible factor (HIF) $1 a$ that is induced by a hypoxic environment, especially within the large lipid-rich necrotic core present in advanced atheroma ${ }^{125,126}$. Hypoxia and HIF1a expression has been shown in vitro to alter macrophage lipid handling and suppress cholesterol efflux via ABCA1 (the ATP-binding cassette subfamily A member 1) in both mouse $^{127}$ and human ${ }^{128}$ macrophages. Moreover, in vitro and ex vivo experiments have implicated hypoxia and HIF1a in driving enhanced glucose uptake, metabolic activity, and polarization of macrophages in human atheroma ${ }^{129}$.

In 2003, Rong and colleagues ${ }^{130}$ reported that cholesterol-loaded vascular smooth muscle cells lost their differentiation markers and instead expressed macrophage markers. A number of experiments in mice, and notably humans ${ }^{131-133}$, have produced in vivo data consistent with these phenomena: $30-40 \%$ of cells classified as plaque macrophages were of vascular smooth muscle cell origin. It is too early to discern the contribution of these cells to the pathological process during atherogenesis, but at least in cell culture, they do not share the molecular signature or the functional properties of activated macrophages ${ }^{134}$.

\section{Targeting of biological processes}

The ability to characterize specifically and target the biological processes central to the pathogenesis of atherosclerosis might prevent progression of disease and development of vulnerable plaque. Even more exciting would be the regression of disease, a possibility suggested by a number of animal models and limited clinical data ${ }^{135}$. Although the targeting of various pathways in experimental models of atherosclerosis has been associated with benefit, clear efficacy in clinical studies has not yet been demonstrated for any single agent (TABLE 2). This apparent lack of efficacy might be related to poor representation of human disease by preclinical models used for evaluation therapeutic agent, or a failure to target patients rationally based on mechanistic staging (disease stage, activity, and severity).

Molecular techniques-The relationship between high-sensitivity CRP (which has been used as a surrogate biomarker for 'inflammation') and atherosclerosis has been the subject of much interest. A number of studies and meta-analyses have demonstrated an association between elevated CRP levels and an increased risk of cardiovascular disease ${ }^{65}$. Indeed, a reduction in CRP in the context of a statin trial was noted to be an independent predictor for outcome $^{136}$. In the JUPITER study ${ }^{137}$ that used high-sensitivity CRP to identify patients at increased risk of vascular events (without elevated LDL-cholesterol levels), patients with high basal high-sensitivity CRP levels were found to be at a significantly increased risk of 
future vascular events. Although the association between high-sensitivity CRP and risk is well established, what exactly this biomarker represents is currently unclear.

Similarly, other circulating proteins including VCAM1 ${ }^{138}$, ICAM $1^{139}$ and P-selectin ${ }^{140}$ have been measured in the plasma of patients and have been shown to be associated with the level of atherosclerosis. But again, in common with high-sensitivity CRP, what these 'downstream' measures represent in uncertain.

The application of cellular biomarkers has been of interest in atherosclerosis and, by virtue of their central role in pathogenesis, circulating monocytes have been the focus of research $^{141}$. Using flow cytometry, the number of circulating $\mathrm{CD} 14^{+} \mathrm{CD} 16^{++}$monocytes has been shown to be inversely related to plasma HDL levels, and CD16 ${ }^{+}$monocytes are proportional to the severity of atherosclerosis ${ }^{142}$, whereas a reduction in the monocyte subpopulation is associated with a reduction in intima-media thickness ${ }^{143}$. Again, these measures do not provide any information about to the underlying pathogenesis of disease. To elucidate the functional characteristics of these 'inflammatory' cells at the level of atherosclerotic plaque, techniques such as laser-capture microdissection (LCM) have been successfully employed to procure intralesional cells in a cell-type-specific and locationspecific fashion. In mice, immuno-LCM coupled with downstream gene or protein expression analysis has been used to study lesional macrophages in various stages of atherogenesis, including atherosclerosis regression. The inflammatory state of plaque macrophages was shown to be dynamically regulated as the severity of disease varied ${ }^{144}$. In humans, studies using LCM on surgical plaque explants has also identified genes implicated in lipid metabolism (such as FABP4 and $L E P$ ) and activation of the adipokine/peroxisome proliferator-activator receptor (PPAR) signalling pathways ${ }^{145}$, as well as a repertoire of inflammatory gene 'signatures' ${ }^{146}$, that might be important in mechanistic staging. Early findings utilizing this approach seem to corroborate observations from genome-wide association studies as well as plaque compositional changes in plaque revealed by highresolution MRI Chai, personal communication. Circulating multivesicular bodies derived from platelets, monocytes, and red blood cells have also been characterized specifically with regard to the miRNA that they contain, and have been shown to have roles in VCAM1 inhibition, activation of plaque macrophages, and in cell-to-cell signalling ${ }^{147}$ that are central to atherosclerosis progression ${ }^{148}$.

Imaging techniques-To overcome some of the limitations of molecular tools, imaging techniques can provide better characterization of pathogenesis while also providing information relating to the anatomical site of disease by specifically targeting components of the process of interest. Conventional imaging modalities (such as CT and MRI) focus on the presence and extent of disease with limited qualitative information (for example, plaque components), but in combination with molecular contrast agents with specific targets, provide the capacity to determine the presence and site of biological processes of interest. For example, MRI after the administration of recombinant HDL particles containing gadolinium $^{149}$ or ultra-small particles of iron oxide ${ }^{150}$ can provide information about macrophage infiltration in plaque, or with microparticles of iron oxide targeting VCAM1 can provide information about endothelial activation - a critical step in atherosclerosis pathogenesis ${ }^{103}$. The use of ${ }^{18}$ FDG-PET in combination with MRI can also improve 
characterization of plaque 'activity', with uptake indicating macrophage activity ${ }^{151}$; high carotid FDG uptake is an independent predictor of cardiovascular events in asymptomatic patients ${ }^{152}$. The use of other tracers, such as ${ }^{18} \mathrm{~F}-\mathrm{NaF}$, have also been used to identify microcalcification in the identification and localization of high-risk coronary plaques ${ }^{153}$. Coregistration of fluorescence molecular tomography and CT with the aid of protease sensors has also been demonstrated to be useful in imaging atherosclerosis in a murine model, and has also been applied to determine response to therapy ${ }^{154}$.

Intravascular fluorescence imaging techniques have increasingly been utilized in clinical practice with intravascular ultrasonography and optical coherence tomography (OCT) increasingly used to identify atherosclerotic plaque and diagnose rupture, erosions, calcific nodules, and the presence and distribution of calcification, lipid, and fibrous tissue ${ }^{12}$. Targeted molecular agents have been used to identify lipid-rich, metabolically active plaque in rabbit arteries ${ }^{155,156}$. Dual-modality OCT and near-infrared autofluorescence (NIRAF) using a specialized OCT-NIRAF catheter has been shown to be feasible and safe in humans and, indeed, NIRAF enhances the sensitivity to detect vulnerable thin-cap fibroatheroma ${ }^{157}$.

In summary, the combination of molecular tools and imaging techniques provides the capacity to characterize active inflammatory processes, the sites of disease, and also enables longitudinal monitoring of disease progression and response to therapy.

\section{Future implications}

In combination with improved understanding, the ability to characterize and mechanistically stage underlying pathological biological processes will enable a more-tailored approach to the management of patients presenting with, or at high risk of, cardiovascular disease. New therapies will be focused on targeting specific pathological processes, especially those related to inflammation, at the appropriate stage of disease and on the basis of current activity. The same tools can also be used to monitor response to treatment ${ }^{158}$ (including toxicity ${ }^{159}$ ). Some preclinical examples include studies in which either IL-13 (which polarizes macrophages to the $\mathrm{M} 2$ state) or a ligand of resolving receptors on macrophages were effective in retarding the progression of atherosclerosis ${ }^{160,161}$.

New biomarkers and imaging techniques could also be applied when evaluating the efficacy of existing and new therapies and be used as surrogate clinical end points (as opposed to the 'hard' clinical end points), resulting in increased statistical power of studies, a reduction in the number of patients that need to be enrolled, reduced cost, and a shorter timescale.

Finally, the majority of reports to date using many of these novel tools have demonstrated only 'proof of concept'. Future studies demonstrating clinical benefits associated with their application in conjunction with technological advances (for example, platform integration and miniaturization) enabling the feasibility of point-of-care testing are required to make these interventions more broadly applicable to patients beyond research centres ${ }^{162}$.

\section{Conclusions}

A number of biological processes contribute to the pathogenesis of cardiovascular disease. These have historically all been termed 'inflammatory', but this oversimplification does not 
accurately convey the heterogeneity of the processes involved. Experimental data suggest that the specific targeting of multiple biological processes can result in attenuation of injury and augmentation of reparative processes. However, despite these very promising results, clear efficacy of anti-inflammatory therapeutics has not been demonstrated in clinical practice. Currently available tools to measure and monitor inflammation are often nonselective, represent downstream sequelae of inflammation, and do not provide any information about presence, extent of activity, or location. By using improved informative techniques to characterize inflammation, a more selective, rational targeted therapeutic approach can be employed. Future efforts will focus on these areas, with a goal of personalized medicine to complement existing treatment strategies, and the ultimate aim of improving clinical outcomes.

\section{Acknowledgments}

Oxford NIHR Biomedical Research Centre (R.P.C.) and the British Heart Foundation Oxford Centre for Research Excellence (N.R., R.P.C.). National Institutes of Health (US) (E.A.F.)

\section{References}

1. Hansson GK. Inflammation, atherosclerosis, and coronary artery disease. The New England journal of medicine. 2005; 352:1685-1695. DOI: 10.1056/NEJMra043430 [PubMed: 15843671]

2. Frangogiannis NG. Regulation of the inflammatory response in cardiac repair. Circulation research. 2012; 110:159-173. DOI: 10.1161/CIRCRESAHA.111.243162 [PubMed: 22223212]

3. Libby P. Inflammation and cardiovascular disease mechanisms. The American journal of clinical nutrition. 2006; 83:456S-460S. [PubMed: 16470012]

4. Biasucci LM, et al. Increasing levels of interleukin (IL)-1Ra and IL-6 during the first 2 days of hospitalization in unstable angina are associated with increased risk of in-hospital coronary events. Circulation. 1999; 99:2079-2084. [PubMed: 10217645]

5. Valgimigli M, et al. Tumor necrosis factor-alpha receptor 1 is a major predictor of mortality and new-onset heart failure in patients with acute myocardial infarction: the Cytokine-Activation and Long-Term Prognosis in Myocardial Infarction (C-ALPHA) study. Circulation. 2005; 111:863-870. DOI: 10.1161/01.CIR.0000155614.35441.69 [PubMed: 15699251]

6. Ridker PM. Clinical application of C-reactive protein for cardiovascular disease detection and prevention. Circulation. 2003; 107:363-369. [PubMed: 12551853]

7. Nahrendorf M, Pittet MJ, Swirski FK. Monocytes: protagonists of infarct inflammation and repair after myocardial infarction. Circulation. 2010; 121:2437-2445. DOI: 10.1161/ CIRCULATIONAHA.109.916346 [PubMed: 20530020]

8. Leuschner F, et al. Therapeutic siRNA silencing in inflammatory monocytes in mice. Nature biotechnology. 2011; 29:1005-1010. DOI: 10.1038/nbt.1989

9. Panizzi P, et al. Impaired infarct healing in atherosclerotic mice with Ly-6C(hi) monocytosis. Journal of the American College of Cardiology. 2010; 55:1629-1638. DOI: 10.1016/j.jacc. 2009.08.089 [PubMed: 20378083]

10. Moore KJ, Sheedy FJ, Fisher EA. Macrophages in atherosclerosis: a dynamic balance. Nature reviews. Immunology. 2013; 13:709-721. DOI: 10.1038/nri3520

11. Bentzon JF, Otsuka F, Virmani R, Falk E. Mechanisms of plaque formation and rupture. Circulation research. 2014; 114:1852-1866. DOI: 10.1161/CIRCRESAHA.114.302721 [PubMed: 24902970]

12. Jia $\mathrm{H}$, et al. In vivo diagnosis of plaque erosion and calcified nodule in patients with acute coronary syndrome by intravascular optical coherence tomography. Journal of the American College of Cardiology. 2013; 62:1748-1758. DOI: 10.1016/j.jacc.2013.05.071 [PubMed: 23810884]

Nat Rev Cardiol. Author manuscript; available in PMC 2017 September 01. 
13. Prondzinsky R, et al. Interleukin-6, -7, -8 and -10 predict outcome in acute myocardial infarction complicated by cardiogenic shock. Clinical research in cardiology : official journal of the German Cardiac Society. 2012; 101:375-384. DOI: 10.1007/s00392-011-0403-3 [PubMed: 22212516]

14. Dimitrijevic O, Stojcevski BD, Ignjatovic S, Singh NM. Serial measurements of C-reactive protein after acute myocardial infarction in predicting one-year outcome. International heart journal. 2006; 47:833-842. [PubMed: 17268118]

15. von Hundelshausen P, Weber C. Platelets as immune cells: bridging inflammation and cardiovascular disease. Circulation research. 2007; 100:27-40. DOI: 10.1161/01.RES. 0000252802.25497.b7 [PubMed: 17204662]

16. Vinten-Johansen J. Involvement of neutrophils in the pathogenesis of lethal myocardial reperfusion injury. Cardiovascular research. 2004; 61:481-497. DOI: 10.1016/j.cardiores.2003.10.011 [PubMed: 14962479]

17. Nahrendorf M, et al. The healing myocardium sequentially mobilizes two monocyte subsets with divergent and complementary functions. The Journal of experimental medicine. 2007; 204:30373047. DOI: 10.1084/jem.20070885 [PubMed: 18025128]

18. Nourshargh S, Renshaw SA, Imhof BA. Reverse Migration of Neutrophils: Where, When, How, and Why? Trends in immunology. 2016; 37:273-286. DOI: 10.1016/j.it.2016.03.006 [PubMed: 27055913]

19. Yan X, et al. Temporal dynamics of cardiac immune cell accumulation following acute myocardial infarction. Journal of molecular and cellular cardiology. 2013; 62:24-35. DOI: 10.1016/j.yjmcc. 2013.04.023 [PubMed: 23644221]

20. Martin JL, Mestril R, Hilal-Dandan R, Brunton LL, Dillmann WH. Small heat shock proteins and protection against ischemic injury in cardiac myocytes. Circulation. 1997; 96:4343-4348. [PubMed: 9416902]

21. Andrassy M, et al. High-mobility group box-1 in ischemia-reperfusion injury of the heart. Circulation. 2008; 117:3216-3226. DOI: 10.1161/CIRCULATIONAHA.108.769331 [PubMed: 18574060]

22. Jiang D, et al. Regulation of lung injury and repair by Toll-like receptors and hyaluronan. Nature medicine. 2005; 11:1173-1179. DOI: 10.1038/nm1315

23. Schoneveld AH, et al. Atherosclerotic lesion development and Toll like receptor 2 and 4 responsiveness. Atherosclerosis. 2008; 197:95-104. DOI: 10.1016/j.atherosclerosis.2007.08.004 [PubMed: 17888930]

24. Beg AA. Endogenous ligands of Toll-like receptors: implications for regulating inflammatory and immune responses. Trends in immunology. 2002; 23:509-512. [PubMed: 12401394]

25. Frantz S, et al. Toll4 (TLR4) expression in cardiac myocytes in normal and failing myocardium. The Journal of clinical investigation. 1999; 104:271-280. DOI: 10.1172/JCI6709 [PubMed: 10430608]

26. Oyama J, et al. Reduced myocardial ischemia-reperfusion injury in toll-like receptor 4-deficient mice. Circulation. 2004; 109:784-789. DOI: 10.1161/01.CIR.0000112575.66565.84 [PubMed: 14970116]

27. Riad A, et al. Toll-like receptor-4 modulates survival by induction of left ventricular remodeling after myocardial infarction in mice. J Immunol. 2008; 180:6954-6961. [PubMed: 18453617]

28. Satoh M, et al. Activated toll-like receptor 4 in monocytes is associated with heart failure after acute myocardial infarction. International journal of cardiology. 2006; 109:226-234. DOI: 10.1016/j.ijcard.2005.06.023 [PubMed: 16051384]

29. Shishido T, et al. Toll-like receptor-2 modulates ventricular remodeling after myocardial infarction. Circulation. 2003; 108:2905-2910. DOI: 10.1161/01.CIR.0000101921.93016.1C [PubMed: 14656915]

30. Ruparelia N, et al. Acute myocardial infarction activates distinct inflammation and proliferation pathways in circulating monocytes, prior to recruitment, and identified through conserved transcriptional responses in mice and humans. European heart journal. 2015; 36:1923-1934. DOI: 10.1093/eurheartj/ehv195 [PubMed: 25982896]

31. Takahashi M. NLRP3 inflammasome as a novel player in myocardial infarction. International heart journal. 2014; 55:101-105. [PubMed: 24632952] 
32. Mezzaroma E, et al. The inflammasome promotes adverse cardiac remodeling following acute myocardial infarction in the mouse. Proceedings of the National Academy of Sciences of the United States of America. 2011; 108:19725-19730. DOI: 10.1073/pnas.1108586108 [PubMed: 22106299]

33. Dreyer WJ, et al. Kinetics of C5a release in cardiac lymph of dogs experiencing coronary artery ischemia-reperfusion injury. Circulation research. 1992; 71:1518-1524. [PubMed: 1423944]

34. Birdsall HH, et al. Complement C5a, TGF-beta 1, and MCP-1, in sequence, induce migration of monocytes into ischemic canine myocardium within the first one to five hours after reperfusion. Circulation. 1997; 95:684-692. [PubMed: 9024158]

35. Distelmaier K, et al. Local complement activation triggers neutrophil recruitment to the site of thrombus formation in acute myocardial infarction. Thrombosis and haemostasis. 2009; 102:564572. DOI: 10.1160/TH09-02-0103 [PubMed: 19718478]

36. Torzewski J, et al. Complement-induced release of monocyte chemotactic protein-1 from human smooth muscle cells. A possible initiating event in atherosclerotic lesion formation. Arteriosclerosis, thrombosis, and vascular biology. 1996; 16:673-677.

37. Lakshminarayanan V, et al. Reactive oxygen intermediates induce monocyte chemotactic protein-1 in vascular endothelium after brief ischemia. The American journal of pathology. 2001; 159:13011311. DOI: 10.1016/S0002-9440(10)62517-5 [PubMed: 11583958]

38. Sellak H, Franzini E, Hakim J, Pasquier C. Reactive oxygen species rapidly increase endothelial ICAM-1 ability to bind neutrophils without detectable upregulation. Blood. 1994; 83:2669-2677. [PubMed: 7513210]

39. Shingu M, et al. Activation of complement in normal serum by hydrogen peroxide and hydrogen peroxide-related oxygen radicals produced by activated neutrophils. Clinical and experimental immunology. 1992; 90:72-78. [PubMed: 1327592]

40. Maekawa N, et al. Improved myocardial ischemia/reperfusion injury in mice lacking tumor necrosis factor-alpha. Journal of the American College of Cardiology. 2002; 39:1229-1235. [PubMed: 11923051]

41. Kurrelmeyer KM, et al. Endogenous tumor necrosis factor protects the adult cardiac myocyte against ischemic-induced apoptosis in a murine model of acute myocardial infarction. Proceedings of the National Academy of Sciences of the United States of America. 2000; 97:5456-5461. DOI: 10.1073/pnas.070036297 [PubMed: 10779546]

42. Saxena A, et al. IL-1 induces proinflammatory leukocyte infiltration and regulates fibroblast phenotype in the infarcted myocardium. J Immunol. 2013; 191:4838-4848. DOI: 10.4049/ jimmunol.1300725 [PubMed: 24078695]

43. Miyao Y, et al. Elevated plasma interleukin-6 levels in patients with acute myocardial infarction. American heart journal. 1993; 126:1299-1304. [PubMed: 8249785]

44. Dawn B, et al. IL-6 plays an obligatory role in late preconditioning via JAK-STAT signaling and upregulation of iNOS and COX-2. Cardiovascular research. 2004; 64:61-71. DOI: 10.1016/ j.cardiores.2004.05.011 [PubMed: 15364614]

45. Swirski FK, et al. Identification of splenic reservoir monocytes and their deployment to inflammatory sites. Science. 2009; 325:612-616. DOI: 10.1126/science.1175202 [PubMed: 19644120]

46. Kim EJ, Kim S, Kang DO, Seo HS. Metabolic activity of the spleen and bone marrow in patients with acute myocardial infarction evaluated by $18 \mathrm{f}$-fluorodeoxyglucose positron emission tomograpic imaging. Circulation. Cardiovascular imaging. 2014; 7:454-460. DOI: 10.1161/ CIRCIMAGING.113.001093 [PubMed: 24488982]

47. Dutta P, et al. Myocardial infarction accelerates atherosclerosis. Nature. 2012; 487:325-329. DOI: 10.1038/nature11260 [PubMed: 22763456]

48. Weinberger T, Schulz C. Myocardial infarction: a critical role of macrophages in cardiac remodeling. Frontiers in physiology. 2015; 6:107. [PubMed: 25904868]

49. Tsujioka H, et al. Impact of heterogeneity of human peripheral blood monocyte subsets on myocardial salvage in patients with primary acute myocardial infarction. Journal of the American College of Cardiology. 2009; 54:130-138. DOI: 10.1016/j.jacc.2009.04.021 [PubMed: 19573729] 
50. Horckmans M, et al. Neutrophils orchestrate post-myocardial infarction healing by polarizing macrophages towards a reparative phenotype. European heart journal. 2016

51. Levick SP, et al. Cardiac mast cells: the centrepiece in adverse myocardial remodelling. Cardiovascular research. 2011; 89:12-19. DOI: 10.1093/cvr/cvq272 [PubMed: 20736239]

52. Hofmann U, et al. Activation of CD4+ T lymphocytes improves wound healing and survival after experimental myocardial infarction in mice. Circulation. 2012; 125:1652-1663. DOI: 10.1161/ CIRCULATIONAHA.111.044164 [PubMed: 22388323]

53. Liuzzo G, et al. Monoclonal T-cell proliferation and plaque instability in acute coronary syndromes. Circulation. 2000; 101:2883-2888. [PubMed: 10869258]

54. Ammirati E, et al. Expansion of T-cell receptor zeta dim effector T cells in acute coronary syndromes. Arteriosclerosis, thrombosis, and vascular biology. 2008; 28:2305-2311. DOI: 10.1161/ATVBAHA.108.174144

55. Zal B, et al. Heat-shock protein 60-reactive CD4+CD28null T cells in patients with acute coronary syndromes. Circulation. 2004; 109:1230-1235. DOI: 10.1161/01.CIR.0000118476.29352.2A [PubMed: 14993140]

56. Liuzzo G, et al. Unusual CD4+CD28null T lymphocytes and recurrence of acute coronary events. Journal of the American College of Cardiology. 2007; 50:1450-1458. DOI: 10.1016/j.jacc. 2007.06.040 [PubMed: 17919564]

57. Mor A, Luboshits G, Planer D, Keren G, George J. Altered status of CD4(+)CD25(+) regulatory T cells in patients with acute coronary syndromes. European heart journal. 2006; 27:2530-2537. DOI: 10.1093/eurheartj/ehl222 [PubMed: 16954132]

58. Blancke F, et al. Systemic inflammation and reperfusion injury in patients with acute myocardial infarction. Mediators of inflammation. 2005; 2005:385-389. DOI: 10.1155/MI.2005.385 [PubMed: 16489260]

59. Kohsaka S, et al. Systemic inflammatory response syndrome after acute myocardial infarction complicated by cardiogenic shock. Archives of internal medicine. 2005; 165:1643-1650. DOI: 10.1001/archinte.165.14.1643 [PubMed: 16043684]

60. Debrunner M, et al. Proinflammatory cytokines in acute myocardial infarction with and without cardiogenic shock. Clinical research in cardiology : official journal of the German Cardiac Society. 2008; 97:298-305. DOI: 10.1007/s00392-007-0626-5 [PubMed: 18491171]

61. Leuschner F, et al. Angiotensin-converting enzyme inhibition prevents the release of monocytes from their splenic reservoir in mice with myocardial infarction. Circulation research. 2010; 107:1364-1373. DOI: 10.1161/CIRCRESAHA.110.227454 [PubMed: 20930148]

62. Majmudar MD, et al. Polymeric nanoparticle PET/MR imaging allows macrophage detection in atherosclerotic plaques. Circulation research. 2013; 112:755-761. DOI: 10.1161/CIRCRESAHA. 111.300576 [PubMed: 23300273]

63. Pearson TA, et al. Markers of inflammation and cardiovascular disease: application to clinical and public health practice: A statement for healthcare professionals from the Centers for Disease Control and Prevention and the American Heart Association. Circulation. 2003; 107:499-511. [PubMed: 12551878]

64. Johnson BD, et al. Serum amyloid A as a predictor of coronary artery disease and cardiovascular outcome in women: the National Heart, Lung, and Blood Institute-Sponsored Women's Ischemia Syndrome Evaluation (WISE). Circulation. 2004; 109:726-732. DOI: 10.1161/01.CIR. 0000115516.54550.B1 [PubMed: 14970107]

65. Danesh J, et al. C-reactive protein and other circulating markers of inflammation in the prediction of coronary heart disease. The New England journal of medicine. 2004; 350:1387-1397. DOI: 10.1056/NEJMoa032804 [PubMed: 15070788]

66. Haim M, Boyko V, Goldbourt U, Battler A, Behar S. Predictive value of elevated white blood cell count in patients with preexisting coronary heart disease: the Bezafibrate Infarction Prevention Study. Archives of internal medicine. 2004; 164:433-439. DOI: 10.1001/archinte.164.4.433 [PubMed: 14980995]

67. Lee CD, et al. White blood cell count and incidence of coronary heart disease and ischemic stroke and mortality from cardiovascular disease in African-American and White men and women: 
atherosclerosis risk in communities study. American journal of epidemiology. 2001; 154:758-764. [PubMed: 11590089]

68. Berk BC, Weintraub WS, Alexander RW. Elevation of C-reactive protein in "active" coronary artery disease. The American journal of cardiology. 1990; 65:168-172. [PubMed: 2296885]

69. Ridker PM, Cushman M, Stampfer MJ, Tracy RP, Hennekens CH. Inflammation, aspirin, and the risk of cardiovascular disease in apparently healthy men. The New England journal of medicine. 1997; 336:973-979. DOI: 10.1056/NEJM199704033361401 [PubMed: 9077376]

70. Ridker PM, Cushman M, Stampfer MJ, Tracy RP, Hennekens CH. Plasma concentration of Creactive protein and risk of developing peripheral vascular disease. Circulation. 1998; 97:425-428. [PubMed: 9490235]

71. Zacho J, et al. Genetically elevated C-reactive protein and ischemic vascular disease. The New England journal of medicine. 2008; 359:1897-1908. DOI: 10.1056/NEJMoa0707402 [PubMed: 18971492]

72. Hirschfield GM, et al. Transgenic human C-reactive protein is not proatherogenic in apolipoprotein E-deficient mice. Proceedings of the National Academy of Sciences of the United States of America. 2005; 102:8309-8314. DOI: 10.1073/pnas.0503202102 [PubMed: 15919817]

73. Passlick B, Flieger D, Ziegler-Heitbrock HW. Identification and characterization of a novel monocyte subpopulation in human peripheral blood. Blood. 1989; 74:2527-2534. [PubMed: 2478233]

74. Subramanian A, et al. Gene set enrichment analysis: a knowledge-based approach for interpreting genome-wide expression profiles. Proceedings of the National Academy of Sciences of the United States of America. 2005; 102:15545-15550. DOI: 10.1073/pnas.0506580102 [PubMed: 16199517]

75. Deng MC, et al. Noninvasive discrimination of rejection in cardiac allograft recipients using gene expression profiling. American journal of transplantation : official journal of the American Society of Transplantation and the American Society of Transplant Surgeons. 2006; 6:150-160. DOI: 10.1111/j.1600-6143.2005.01175.x

76. Golub TR, et al. Molecular classification of cancer: class discovery and class prediction by gene expression monitoring. Science. 1999; 286:531-537. [PubMed: 10521349]

77. van 't Veer LJ, et al. Gene expression profiling predicts clinical outcome of breast cancer. Nature. 2002; 415:530-536. DOI: 10.1038/415530a [PubMed: 11823860]

78. Bendall SC, et al. Single-cell mass cytometry of differential immune and drug responses across a human hematopoietic continuum. Science. 2011; 332:687-696. DOI: 10.1126/science.1198704 [PubMed: 21551058]

79. Haas B, et al. Proteomic analysis of plasma samples from patients with acute myocardial infarction identifies haptoglobin as a potential prognostic biomarker. Journal of proteomics. 2011; 75:229236. DOI: 10.1016/j.jprot.2011.06.028 [PubMed: 21767674]

80. Shah SH, Newgard CB. Integrated metabolomics and genomics: systems approaches to biomarkers and mechanisms of cardiovascular disease. Circulation. Cardiovascular genetics. 2015; 8:410-419. DOI: 10.1161/CIRCGENETICS.114.000223 [PubMed: 25901039]

81. Stegemann C, et al. Lipidomics profiling and risk of cardiovascular disease in the prospective population-based Bruneck study. Circulation. 2014; 129:1821-1831. DOI: 10.1161/ CIRCULATIONAHA.113.002500 [PubMed: 24622385]

82. Malik ZA, et al. Cardiac myocyte exosomes: stability, HSP60, and proteomics. American journal of physiology. Heart and circulatory physiology. 2013; 304:H954-965. DOI: 10.1152/ajpheart. 00835.2012 [PubMed: 23376832]

83. Valadi H, et al. Exosome-mediated transfer of mRNAs and microRNAs is a novel mechanism of genetic exchange between cells. Nature cell biology. 2007; 9:654-659. DOI: 10.1038/ncb1596 [PubMed: 17486113]

84. Muralidharan-Chari V, Clancy JW, Sedgwick A, D’Souza-Schorey C. Microvesicles: mediators of extracellular communication during cancer progression. Journal of cell science. 2010; 123:16031611. DOI: 10.1242/jcs.064386 [PubMed: 20445011] 
85. Wickman GR, et al. Blebs produced by actin-myosin contraction during apoptosis release damageassociated molecular pattern proteins before secondary necrosis occurs. Cell death and differentiation. 2013; 20:1293-1305. DOI: 10.1038/cdd.2013.69 [PubMed: 23787996]

86. Wickman G, Julian L, Olson MF. How apoptotic cells aid in the removal of their own cold dead bodies. Cell death and differentiation. 2012; 19:735-742. DOI: 10.1038/cdd.2012.25 [PubMed: 22421963]

87. Tans G, et al. Comparison of anticoagulant and procoagulant activities of stimulated platelets and platelet-derived microparticles. Blood. 1991; 77:2641-2648. [PubMed: 2043766]

88. Taraboletti G, et al. Shedding of the matrix metalloproteinases MMP-2, MMP-9, and MT1-MMP as membrane vesicle-associated components by endothelial cells. The American journal of pathology. 2002; 160:673-680. DOI: 10.1016/S0002-9440(10)64887-0 [PubMed: 11839588]

89. Boulanger CM, et al. Circulating microparticles from patients with myocardial infarction cause endothelial dysfunction. Circulation. 2001; 104:2649-2652. [PubMed: 11723013]

90. Deng ZB, et al. Adipose tissue exosome-like vesicles mediate activation of macrophage-induced insulin resistance. Diabetes. 2009; 58:2498-2505. DOI: 10.2337/db09-0216 [PubMed: 19675137]

91. Mesri M, Altieri DC. Endothelial cell activation by leukocyte microparticles. J Immunol. 1998; 161:4382-4387. [PubMed: 9780216]

92. Martin S, et al. Shed membrane particles from T lymphocytes impair endothelial function and regulate endothelial protein expression. Circulation. 2004; 109:1653-1659. DOI: 10.1161/01.CIR. 0000124065.31211.6E [PubMed: 15023873]

93. Quiat D, Olson EN. MicroRNAs in cardiovascular disease: from pathogenesis to prevention and treatment. The Journal of clinical investigation. 2013; 123:11-18. DOI: 10.1172/JCI62876 [PubMed: 23281405]

94. Zhang Y, et al. Secreted monocytic miR-150 enhances targeted endothelial cell migration. Molecular cell. 2010; 39:133-144. DOI: 10.1016/j.molcel.2010.06.010 [PubMed: 20603081]

95. Bye A, et al. Circulating microRNAs predict future fatal myocardial infarction in healthy individuals - The HUNT study. Journal of molecular and cellular cardiology. 2016; 97:162-168. DOI: 10.1016/j.yjmcc.2016.05.009 [PubMed: 27192016]

96. Yilmaz A, et al. Imaging of myocardial infarction using ultrasmall superparamagnetic iron oxide nanoparticles: a human study using a multi-parametric cardiovascular magnetic resonance imaging approach. European heart journal. 2013; 34:462-475. DOI: 10.1093/eurheartj/ehs366 [PubMed: 23103659]

97. Alam SR, et al. Ultrasmall superparamagnetic particles of iron oxide in patients with acute myocardial infarction: early clinical experience. Circulation. Cardiovascular imaging. 2012; 5:559-565. DOI: 10.1161/CIRCIMAGING.112.974907 [PubMed: 22875883]

98. Lee WW, et al. PET/MRI of inflammation in myocardial infarction. Journal of the American College of Cardiology. 2012; 59:153-163. DOI: 10.1016/j.jacc.2011.08.066 [PubMed: 22222080]

99. Jung K, et al. Endoscopic time-lapse imaging of immune cells in infarcted mouse hearts. Circulation research. 2013; 112:891-899. DOI: 10.1161/CIRCRESAHA.111.300484 [PubMed: 23392842]

100. Wollenweber $\mathrm{T}$, et al. Characterizing the inflammatory tissue response to acute myocardial infarction by clinical multimodality noninvasive imaging. Circulation. Cardiovascular imaging. 2014; 7:811-818. DOI: 10.1161/CIRCIMAGING.114.001689 [PubMed: 25049056]

101. Rischpler C, et al. Prospective Evaluation of 18F-Fluorodeoxyglucose Uptake in Postischemic Myocardium by Simultaneous Positron Emission Tomography/Magnetic Resonance Imaging as a Prognostic Marker of Functional Outcome. Circulation. Cardiovascular imaging. 2016; 9:e004316. [PubMed: 27056601]

102. McAteer MA, et al. In vivo magnetic resonance imaging of acute brain inflammation using microparticles of iron oxide. Nature medicine. 2007; 13:1253-1258. DOI: 10.1038/nm1631

103. McAteer MA, et al. A leukocyte-mimetic magnetic resonance imaging contrast agent homes rapidly to activated endothelium and tracks with atherosclerotic lesion macrophage content. Arteriosclerosis, thrombosis, and vascular biology. 2012; 32:1427-1435. DOI: 10.1161/ ATVBAHA.111.241844 
104. Akhtar AM, et al. In vivo quantification of VCAM-1 expression in renal ischemia reperfusion injury using non-invasive magnetic resonance molecular imaging. PloS one. 2010; 5:e12800. [PubMed: 20877722]

105. Sahul ZH, et al. Targeted imaging of the spatial and temporal variation of matrix metalloproteinase activity in a porcine model of postinfarct remodeling: relationship to myocardial dysfunction. Circulation. Cardiovascular imaging. 2011; 4:381-391. DOI: 10.1161/ CIRCIMAGING.110.961854 [PubMed: 21505092]

106. Ross R. Atherosclerosis--an inflammatory disease. The New England journal of medicine. 1999; 340:115-126. DOI: 10.1056/NEJM199901143400207 [PubMed: 9887164]

107. Choudhury RP, Lee JM, Greaves DR. Mechanisms of disease: macrophage-derived foam cells emerging as therapeutic targets in atherosclerosis. Nature clinical practice. Cardiovascular medicine. 2005; 2:309-315. DOI: 10.1038/ncpcardio0195

108. Tabas I, Williams KJ, Boren J. Subendothelial lipoprotein retention as the initiating process in atherosclerosis: update and therapeutic implications. Circulation. 2007; 116:1832-1844. DOI: 10.1161/CIRCULATIONAHA.106.676890 [PubMed: 17938300]

109. van Furth R, Cohn ZA. The origin and kinetics of mononuclear phagocytes. The Journal of experimental medicine. 1968; 128:415-435. [PubMed: 5666958]

110. Cybulsky MI, Gimbrone MA Jr. Endothelial expression of a mononuclear leukocyte adhesion molecule during atherogenesis. Science. 1991; 251:788-791. [PubMed: 1990440]

111. Tacke F, et al. Monocyte subsets differentially employ CCR2, CCR5, and CX3CR1 to accumulate within atherosclerotic plaques. Journal of Clinical Investigation. 2007; 117:185-194. DOI: 10.1172/jci28549 [PubMed: 17200718]

112. Combadiere C, et al. Combined Inhibition of CCL2, CX3CR1, and CCR5 Abrogates Ly6Chi and Ly6Clo Monocytosis and Almost Abolishes Atherosclerosis in Hypercholesterolemic Mice. Circulation. 2008; 117:1649-1657. DOI: 10.1161/circulationaha.107.745091 [PubMed: 18347211]

113. Heidt T, et al. Chronic variable stress activates hematopoietic stem cells. Nature medicine. 2014; 20:754-758. DOI: 10.1038/nm.3589

114. Ley K, Miller YI, Hedrick CC. Monocyte and macrophage dynamics during atherogenesis. Arteriosclerosis, thrombosis, and vascular biology. 2011; 31:1506-1516. DOI: 10.1161/ ATVBAHA.110.221127

115. Robbins CS, et al. Local proliferation dominates lesional macrophage accumulation in atherosclerosis. Nature medicine. 2013; 19:1166-1172. DOI: 10.1038/nm.3258

116. Khallou-Laschet J, et al. Macrophage plasticity in experimental atherosclerosis. PloS one. 2010; 5:e8852. [PubMed: 20111605]

117. Schissel SL, et al. Rabbit aorta and human atherosclerotic lesions hydrolyze the sphingomyelin of retained low-density lipoprotein. Proposed role for arterial-wall sphingomyelinase in subendothelial retention and aggregation of atherogenic lipoproteins. The Journal of clinical investigation. 1996; 98:1455-1464. DOI: 10.1172/JCI118934 [PubMed: 8823312]

118. Barthwal MK, et al. Fluid-phase pinocytosis of native low density lipoprotein promotes murine M-CSF differentiated macrophage foam cell formation. PloS one. 2013; 8:e58054. [PubMed: 23536783]

119. Shao BZ, Han BZ, Zeng YX, Su DF, Liu C. The roles of macrophage autophagy in atherosclerosis. Acta Pharmacol Sin. 2016; 37:150-156. DOI: 10.1038/aps.2015.87 [PubMed: 26750103]

120. Chan KF, Siegel MR, Lenardo JM. Signaling by the TNF receptor superfamily and T cell homeostasis. Immunity. 2000; 13:419-422. [PubMed: 11070160]

121. Ait-Oufella H, Taleb S, Mallat Z, Tedgui A. Recent Advances on the Role of Cytokines in Atherosclerosis. Arteriosclerosis, thrombosis, and vascular biology. 2011; 31:969-979. DOI: 10.1161/atvbaha.110.207415

122. Gharavi NM, et al. Role of the Jak/STAT pathway in the regulation of interleukin- 8 transcription by oxidized phospholipids in vitro and in atherosclerosis in vivo. The Journal of biological chemistry. 2007; 282:31460-31468. DOI: 10.1074/jbc.M704267200 [PubMed: 17726017] 
123. Michel JB, Virmani R, Arbustini E, Pasterkamp G. Intraplaque haemorrhages as the trigger of plaque vulnerability. European heart journal. 2011; 32:1977-1985. DOI: 10.1093/eurheartj/ ehr054 [PubMed: 21398643]

124. Hellings WE, et al. Composition of Carotid Atherosclerotic Plaque Is Associated With Cardiovascular Outcome: A Prognostic Study. Circulation. 2010; 121:1941-1950. DOI: 10.1161/ circulationaha.109.887497 [PubMed: 20404256]

125. Vink A, et al. HIF-1alpha expression is associated with an atheromatous inflammatory plaque phenotype and upregulated in activated macrophages. Atherosclerosis. 2007; 195:e69-e75. DOI: 10.1016/j.atherosclerosis.2007.05.026 [PubMed: 17606258]

126. Sluimer JC, Daemen MJ. Novel concepts in atherogenesis: angiogenesis and hypoxia in atherosclerosis. J Pathol. 2009; 218:7-29. DOI: 10.1002/path.2518 [PubMed: 19309025]

127. Parathath S, et al. Hypoxia Is Present in Murine Atherosclerotic Plaques and Has Multiple Adverse Effects on Macrophage Lipid Metabolism. Circulation research. 2011

128. Ugocsai P, et al. HIF-1beta determines ABCA1 expression under hypoxia in human macrophages. The International Journal of Biochemistry \& Cell Biology. 2010; 42:241-252. DOI: 10.1016/ j.biocel.2009.10.002 [PubMed: 19828131]

129. Folco E, et al. Hypoxia but not inflammation augments glucose uptake in human macrophages. Journal of American College of Cardiology. 2011; 58:603-614. DOI: 10.1016/j.jacc.2011.03.044

130. Rong JX, Shapiro M, Trogan E, Fisher EA. Transdifferentiation of mouse aortic smooth muscle cells to a macrophage-like state after cholesterol loading. Proceedings of the National Academy of Sciences of the United States of America. 2003; 100:13531-13536. DOI: 10.1073/pnas. 1735526100 [PubMed: 14581613]

131. Feil S, et al. Transdifferentiation of vascular smooth muscle cells to macrophage-like cells during atherogenesis. Circulation research. 2014; 115:662-667. DOI: 10.1161/CIRCRESAHA. 115.304634 [PubMed: 25070003]

132. Shankman LS, et al. KLF4-dependent phenotypic modulation of smooth muscle cells has a key role in atherosclerotic plaque pathogenesis. Nature medicine. 2015; 21:628-637. DOI: 10.1038/nm.3866

133. Allahverdian S, Chehroudi AC, McManus BM, Abraham T, Francis GA. Contribution of intimal smooth muscle cells to cholesterol accumulation and macrophage-like cells in human atherosclerosis. Circulation. 2014; 129:1551-1559. DOI: 10.1161/CIRCULATIONAHA. 113.005015 [PubMed: 24481950]

134. Vengrenyuk Y, et al. Cholesterol loading reprograms the microRNA-143/145-myocardin axis to convert aortic smooth muscle cells to a dysfunctional macrophage-like phenotype. Arteriosclerosis, thrombosis, and vascular biology. 2015; 35:535-546. DOI: 10.1161/ ATVBAHA.114.304029

135. Williams KJ, Feig JE, Fisher EA. Rapid regression of atherosclerosis: insights from the clinical and experimental literature. Nature clinical practice. Cardiovascular medicine. 2008; 5:91-102. DOI: $10.1038 /$ ncpcardio1086

136. Nissen SE, et al. Statin therapy, LDL cholesterol, C-reactive protein, and coronary artery disease. The New England journal of medicine. 2005; 352:29-38. DOI: 10.1056/NEJMoa042000 [PubMed: 15635110]

137. Ridker PM, et al. Rosuvastatin to prevent vascular events in men and women with elevated Creactive protein. The New England journal of medicine. 2008; 359:2195-2207. DOI: 10.1056/ NEJMoa0807646 [PubMed: 18997196]

138. Semaan HB, et al. Soluble VCAM-1 and E-selectin, but not ICAM-1 discriminate endothelial injury in patients with documented coronary artery disease. Cardiology. 2000; 93:7-10. 6995. [PubMed: 10894900]

139. Hwang SJ, et al. Circulating adhesion molecules VCAM-1, ICAM-1, and E-selectin in carotid atherosclerosis and incident coronary heart disease cases: the Atherosclerosis Risk In Communities (ARIC) study. Circulation. 1997; 96:4219-4225. [PubMed: 9416885]

140. Blann AD, Lip GY, Beevers DG, McCollum CN. Soluble P-selectin in atherosclerosis: a comparison with endothelial cell and platelet markers. Thrombosis and haemostasis. 1997; 77:1077-1080. [PubMed: 9241735] 
141. Swirski FK, Weissleder R, Pittet MJ. Heterogeneous in vivo behavior of monocyte subsets in atherosclerosis. Arteriosclerosis, thrombosis, and vascular biology. 2009; 29:1424-1432. DOI: 10.1161/ATVBAHA.108.180521

142. Schlitt A, et al. CD14+CD16+ monocytes in coronary artery disease and their relationship to serum TNF-alpha levels. Thrombosis and haemostasis. 2004; 92:419-424. DOI: 10.1160/ TH04-02-0095 [PubMed: 15269840]

143. Poitou C, et al. CD14dimCD16+ and CD14+CD16+ monocytes in obesity and during weight loss: relationships with fat mass and subclinical atherosclerosis. Arteriosclerosis, thrombosis, and vascular biology. 2011; 31:2322-2330. DOI: 10.1161/ATVBAHA.111.230979

144. Feig JE, et al. Reversal of hyperlipidemia with a genetic switch favorably affects the content and inflammatory state of macrophages in atherosclerotic plaques. Circulation. 2011; 123:989-998. DOI: 10.1161/CIRCULATIONAHA.110.984146 [PubMed: 21339485]

145. Lee $\mathrm{K}$, et al. Increased expression of fatty acid binding protein 4 and leptin in resident macrophages characterises atherosclerotic plaque rupture. Atherosclerosis. 2013; 226:74-81. DOI: 10.1016/j.atherosclerosis.2012.09.037 [PubMed: 23122912]

146. Puig $\mathrm{O}$, et al. A gene expression signature that classifies human atherosclerotic plaque by relative inflammation status. Circulation. Cardiovascular genetics. 2011; 4:595-604. DOI: 10.1161/ CIRCGENETICS.111.960773 [PubMed: 22010137]

147. Hulsmans M, Holvoet P. MicroRNA-containing microvesicles regulating inflammation in association with atherosclerotic disease. Cardiovascular research. 2013; 100:7-18. DOI: 10.1093/cvr/cvt161 [PubMed: 23774505]

148. Rautou PE, et al. Microparticles from human atherosclerotic plaques promote endothelial ICAM-1-dependent monocyte adhesion and transendothelial migration. Circulation research. 2011; 108:335-343. DOI: 10.1161/CIRCRESAHA.110.237420 [PubMed: 21164106]

149. Skajaa T, et al. High-density lipoprotein-based contrast agents for multimodal imaging of atherosclerosis. Arteriosclerosis, thrombosis, and vascular biology. 2010; 30:169-176. DOI: 10.1161/ATVBAHA.108.179275

150. Ruehm SG, Corot C, Vogt P, Cristina H, Debatin JF. Ultrasmall superparamagnetic iron oxideenhanced MR imaging of atherosclerotic plaque in hyperlipidemic rabbits. Academic radiology. 2002; 9(Suppl 1):S143-144. [PubMed: 12019852]

151. Tarkin JM, Joshi FR, Rudd JH. PET imaging of inflammation in atherosclerosis. Nature reviews. Cardiology. 2014; 11:443-457. DOI: 10.1038/nrcardio.2014.80 [PubMed: 24913061]

152. Moon SH, et al. Carotid FDG Uptake Improves Prediction of Future Cardiovascular Events in Asymptomatic Individuals. JACC. Cardiovascular imaging. 2015; 8:949-956. DOI: 10.1016/ j.jcmg.2015.06.002 [PubMed: 26189117]

153. Joshi NV, et al. 18F-fluoride positron emission tomography for identification of ruptured and high-risk coronary atherosclerotic plaques: a prospective clinical trial. Lancet. 2014; 383:705713. DOI: 10.1016/S0140-6736(13)61754-7 [PubMed: 24224999]

154. Nahrendorf M, et al. Hybrid in vivo FMT-CT imaging of protease activity in atherosclerosis with customized nanosensors. Arteriosclerosis, thrombosis, and vascular biology. 2009; 29:14441451. DOI: 10.1161/ATVBAHA.109.193086

155. Vinegoni $\mathrm{C}$, et al. Indocyanine green enables near-infrared fluorescence imaging of lipid-rich, inflamed atherosclerotic plaques. Sci Transl Med. 2011; 3:84ra45.

156. Lee S, et al. Fully integrated high-speed intravascular optical coherence tomography/near-infrared fluorescence structural/molecular imaging in vivo using a clinically available near-infrared fluorescence-emitting indocyanine green to detect inflamed lipid-rich atheromata in coronarysized vessels. Circ Cardiovasc Interv. 2014; 7:560-569. DOI: 10.1161/CIRCINTERVENTIONS. 114.001498 [PubMed: 25074255]

157. Ughi GJ, et al. Clinical Characterization of Coronary Atherosclerosis With Dual-Modality OCT and Near-Infrared Autofluorescence Imaging. JACC Cardiovasc Imaging. 2016

158. Santos R, et al. Dynamics of interferon-beta modulated mRNA biomarkers in multiple sclerosis patients with anti-interferon-beta neutralizing antibodies. Journal of neuroimmunology. 2006; 176:125-133. DOI: 10.1016/j.jneuroim.2006.03.019 [PubMed: 16698090] 
159. Yang Y, Blomme EA, Waring JF. Toxicogenomics in drug discovery: from preclinical studies to clinical trials. Chemico-biological interactions. 2004; 150:71-85. DOI: 10.1016/j.cbi. 2004.09.013 [PubMed: 15522262]

160. Cardilo-Reis L, et al. Interleukin-13 protects from atherosclerosis and modulates plaque composition by skewing the macrophage phenotype. EMBO molecular medicine. 2012; 4:10721086. DOI: 10.1002/emmm.201201374 [PubMed: 23027612]

161. Fredman G, et al. Targeted nanoparticles containing the proresolving peptide Ac2-26 protect against advanced atherosclerosis in hypercholesterolemic mice. Science translational medicine. 2015; 7:275ra220.

162. Barrett PM, Topol EJ. Pharmacogenetics: Point-of-care genetic testing--a new frontier explored. Nature reviews. Cardiology. 2012; 9:315-316. DOI: 10.1038/nrcardio.2012.63

163. Kobara M, et al. Antibody against interleukin-6 receptor attenuates left ventricular remodelling after myocardial infarction in mice. Cardiovascular research. 2010; 87:424-430. DOI: 10.1093/cvr/cvq078 [PubMed: 20211866]

164. Kleveland O, et al. Effect of a single dose of the interleukin-6 receptor antagonist tocilizumab on inflammation and troponin $\mathrm{T}$ release in patients with non-ST-elevation myocardial infarction: a double-blind, randomized, placebo-controlled phase 2 trial. European heart journal. 2016

165. Toldo S, et al. Interleukin-1beta blockade improves cardiac remodelling after myocardial infarction without interrupting the inflammasome in the mouse. Exp Physiol. 2013; 98:734-745. DOI: 10.1113/expphysiol.2012.069831 [PubMed: 23180808]

166. Hwang MW, et al. Neutralization of interleukin-1beta in the acute phase of myocardial infarction promotes the progression of left ventricular remodeling. Journal of the American College of Cardiology. 2001; 38:1546-1553. [PubMed: 11691538]

167. Abbate A, et al. Anakinra, a recombinant human interleukin-1 receptor antagonist, inhibits apoptosis in experimental acute myocardial infarction. Circulation. 2008; 117:2670-2683. DOI: 10.1161/CIRCULATIONAHA.107.740233 [PubMed: 18474815]

168. Morton AC, et al. The effect of interleukin-1 receptor antagonist therapy on markers of inflammation in non-ST elevation acute coronary syndromes: the MRC-ILA Heart Study. European heart journal. 2015; 36:377-384. DOI: 10.1093/eurheartj/ehu272 [PubMed: 25079365]

169. Abbate A, et al. Comparative safety of interleukin-1 blockade with anakinra in patients with STsegment elevation acute myocardial infarction (from the VCU-ART and VCU-ART2 pilot studies). The American journal of cardiology. 2015; 115:288-292. DOI: 10.1016/j.amjcard. 2014.11.003 [PubMed: 25482680]

170. Sugano M, Tsuchida K, Hata T, Makino N. In vivo transfer of soluble TNF-alpha receptor 1 gene improves cardiac function and reduces infarct size after myocardial infarction in rats. FASEB journal : official publication of the Federation of American Societies for Experimental Biology. 2004; 18:911-913. DOI: 10.1096/fj.03-1148fje [PubMed: 15117889]

171. Padfield GJ, et al. Cardiovascular effects of tumour necrosis factor alpha antagonism in patients with acute myocardial infarction: a first in human study. Heart. 2013; 99:1330-1335. DOI: 10.1136/heartjnl-2013-303648 [PubMed: 23574969]

172. Matsumura S, et al. Targeted deletion or pharmacological inhibition of MMP-2 prevents cardiac rupture after myocardial infarction in mice. The Journal of clinical investigation. 2005; 115:599609. DOI: 10.1172/JCI22304 [PubMed: 15711638]

173. Hudson MP, et al. Effects of selective matrix metalloproteinase inhibitor (PG-116800) to prevent ventricular remodeling after myocardial infarction: results of the PREMIER (Prevention of Myocardial Infarction Early Remodeling) trial. Journal of the American College of Cardiology. 2006; 48:15-20. DOI: 10.1016/j.jacc.2006.02.055 [PubMed: 16814643]

174. Ducharme A, et al. Targeted deletion of matrix metalloproteinase- 9 attenuates left ventricular enlargement and collagen accumulation after experimental myocardial infarction. The Journal of clinical investigation. 2000; 106:55-62. DOI: 10.1172/JCI8768 [PubMed: 10880048]

175. Cerisano G, et al. Early short-term doxycycline therapy in patients with acute myocardial infarction and left ventricular dysfunction to prevent the ominous progression to adverse remodelling: the TIPTOP trial. European heart journal. 2014; 35:184-191. DOI: 10.1093/ eurheartj/eht420 [PubMed: 24104875] 
176. Slagman AC, et al. Specific removal of C-reactive protein by apheresis in a porcine cardiac infarction model. Blood purification. 2011; 31:9-17. DOI: 10.1159/000320763 [PubMed: 21135544]

177. Wang K, et al. Recombinant soluble P-selectin glycoprotein ligand-Ig (rPSGL-Ig) attenuates infarct size and myeloperoxidase activity in a canine model of ischemia-reperfusion. Thrombosis and haemostasis. 2002; 88:149-154. [PubMed: 12152656]

178. Tardif JC, et al. Effects of the P-selectin antagonist inclacumab on myocardial damage after percutaneous coronary intervention for non-ST-segment elevation myocardial infarction: results of the SELECT-ACS trial. Journal of the American College of Cardiology. 2013; 61:2048-2055. DOI: 10.1016/j.jacc.2013.03.003 [PubMed: 23500230]

179. Toldo S, et al. Alpha-1 antitrypsin inhibits caspase-1 and protects from acute myocardial ischemia-reperfusion injury. Journal of molecular and cellular cardiology. 2011; 51:244-251. DOI: 10.1016/j.yjmcc.2011.05.003 [PubMed: 21600901]

180. Abbate A, et al. Effects of Prolastin C (Plasma-Derived Alpha-1 Antitrypsin) on the acute inflammatory response in patients with ST-segment elevation myocardial infarction (from the VCU-alpha 1-RT pilot study). The American journal of cardiology. 2015; 115:8-12. DOI: 10.1016/j.amjcard.2014.09.043 [PubMed: 25456867]

181. Weisman HF, et al. Soluble human complement receptor type 1: in vivo inhibitor of complement suppressing post-ischemic myocardial inflammation and necrosis. Science. 1990; 249:146-151. [PubMed: 2371562]

182. Investigators, A. A. et al. Pexelizumab for acute ST-elevation myocardial infarction in patients undergoing primary percutaneous coronary intervention: a randomized controlled trial. JAMA : the journal of the American Medical Association. 2007; 297:43-51. DOI: 10.1001/jama.297.1.43 [PubMed: 17200474]

183. Arai M, et al. An anti-CD18 antibody limits infarct size and preserves left ventricular function in dogs with ischemia and 48-hour reperfusion. Journal of the American College of Cardiology. 1996; 27:1278-1285. [PubMed: 8609356]

184. Aversano T, Zhou W, Nedelman M, Nakada M, Weisman H. A chimeric IgG4 monoclonal antibody directed against CD18 reduces infarct size in a primate model of myocardial ischemia and reperfusion. Journal of the American College of Cardiology. 1995; 25:781-788. DOI: 10.1016/0735-1097(94)00443-T [PubMed: 7860929]

185. Faxon DP, et al. The effect of blockade of the CD11/CD18 integrin receptor on infarct size in patients with acute myocardial infarction treated with direct angioplasty: the results of the HALTMI study. Journal of the American College of Cardiology. 2002; 40:1199-1204. [PubMed: 12383565]

186. Baran KW, et al. Double-blind, randomized trial of an anti-CD18 antibody in conjunction with recombinant tissue plasminogen activator for acute myocardial infarction: limitation of myocardial infarction following thrombolysis in acute myocardial infarction (LIMIT AMI) study. Circulation. 2001; 104:2778-2783. [PubMed: 11733394]

187. Gurantz D, et al. Etanercept or intravenous immunoglobulin attenuates expression of genes involved in post-myocardial infarction remodeling. Cardiovascular research. 2005; 67:106-115. DOI: 10.1016/j.cardiores.2005.02.016 [PubMed: 15949474]

188. Gullestad L, Wiseth R. Effect of the interleukin-6 receptor antagonist tocilizumab in non-ST elevation myocardial infarction. Clinical Trials number: NCT01491074. 2013

189. O'Donoghue ML, et al. Effect of Losmapimod on Cardiovascular Outcomes in Patients Hospitalized With Acute Myocardial Infarction: A Randomized Clinical Trial. JAMA : the journal of the American Medical Association. 2016; 315:1591-1599. DOI: 10.1001/jama. 2016.3609 [PubMed: 27043082]

190. Elhage R, et al. Differential effects of interleukin-1 receptor antagonist and tumor necrosis factor binding protein on fatty-streak formation in apolipoprotein E-deficient mice. Circulation. 1998; 97:242-244. [PubMed: 9462524]

191. Devlin CM, Kuriakose G, Hirsch E, Tabas I. Genetic alterations of IL-1 receptor antagonist in mice affect plasma cholesterol level and foam cell lesion size. Proceedings of the National Academy of Sciences of the United States of America. 2002; 99:6280-6285. DOI: 10.1073/pnas. 092324399 [PubMed: 11983917] 
192. Branen L, et al. Inhibition of tumor necrosis factor-alpha reduces atherosclerosis in apolipoprotein E knockout mice. Arteriosclerosis, thrombosis, and vascular biology. 2004; 24:2137-2142. DOI: 10.1161/01.ATV.0000143933.20616.1b

193. Maki-Petaja KM, et al. Anti-tumor necrosis factor-alpha therapy reduces aortic inflammation and stiffness in patients with rheumatoid arthritis. Circulation. 2012; 126:2473-2480. DOI: 10.1161/ CIRCULATIONAHA.112.120410 [PubMed: 23095282]

194. Davenport P, Tipping PG. The role of interleukin-4 and interleukin-12 in the progression of atherosclerosis in apolipoprotein E-deficient mice. The American journal of pathology. 2003; 163:1117-1125. DOI: 10.1016/S0002-9440(10)63471-2 [PubMed: 12937153]

195. Papp KA, et al. Long-term safety of ustekinumab in patients with moderate-to-severe psoriasis: final results from 5 years of follow-up. The British journal of dermatology. 2013; 168:844-854. DOI: 10.1111/bjd.12214 [PubMed: 23301632]

196. Erbel C, et al. Inhibition of IL-17A attenuates atherosclerotic lesion development in apoEdeficient mice. J Immunol. 2009; 183:8167-8175. DOI: 10.4049/jimmunol.0901126 [PubMed: 20007582]

197. van de Kerkhof PC, et al. Secukinumab long-term safety experience: A pooled analysis of 10 phase II and III clinical studies in patients with moderate to severe plaque psoriasis. Journal of the American Academy of Dermatology. 2016; 75:83-98 e84. DOI: 10.1016/j.jaad.2016.03.024 [PubMed: 27180926]

198. Jagavelu K, et al. Systemic deficiency of the MAP kinase-activated protein kinase 2 reduces atherosclerosis in hypercholesterolemic mice. Circulation research. 2007; 101:1104-1112. DOI: 10.1161/CIRCRESAHA.107.156075 [PubMed: 17885219]

199. Elkhawad M, et al. Effects of p38 mitogen-activated protein kinase inhibition on vascular and systemic inflammation in patients with atherosclerosis. JACC. Cardiovascular imaging. 2012; 5:911-922. DOI: 10.1016/j.jcmg.2012.02.016 [PubMed: 22974804]

200. Bursill CA, Choudhury RP, Ali Z, Greaves DR, Channon KM. Broad-spectrum CC-chemokine blockade by gene transfer inhibits macrophage recruitment and atherosclerotic plaque formation in apolipoprotein E-knockout mice. Circulation. 2004; 110:2460-2466. DOI: 10.1161/01.CIR. 0000145122.58420.CO [PubMed: 15477414]

201. Dong ZM, et al. The combined role of P- and E-selectins in atherosclerosis. The Journal of clinical investigation. 1998; 102:145-152. DOI: 10.1172/JCI3001 [PubMed: 9649568]

202. Stahli BE, et al. Effects of P-Selectin Antagonist Inclacumab in Patients Undergoing Coronary Artery Bypass Graft Surgery: SELECT-CABG Trial. Journal of the American College of Cardiology. 2016; 67:344-346. DOI: 10.1016/j.jacc.2015.10.071 [PubMed: 26796402]

203. Park JG, et al. Evaluation of VCAM-1 antibodies as therapeutic agent for atherosclerosis in apolipoprotein E-deficient mice. Atherosclerosis. 2013; 226:356-363. DOI: 10.1016/ j.atherosclerosis.2012.11.029 [PubMed: 23245509]

204. Fraser H, et al. Varespladib (A-002), a secretory phospholipase A2 inhibitor, reduces atherosclerosis and aneurysm formation in ApoE-/- mice. Journal of cardiovascular pharmacology. 2009; 53:60-65. DOI: 10.1097/FJC.0b013e318195bfbc [PubMed: 19129734]

205. Nicholls SJ, et al. Varespladib and cardiovascular events in patients with an acute coronary syndrome: the VISTA-16 randomized clinical trial. JAMA : the journal of the American Medical Association. 2014; 311:252-262. DOI: 10.1001/jama.2013.282836 [PubMed: 24247616]

206. Wilensky RL, et al. Inhibition of lipoprotein-associated phospholipase A2 reduces complex coronary atherosclerotic plaque development. Nature medicine. 2008; 14:1059-1066. DOI: 10.1038/nm. 1870

207. Investigators, S. et al. Darapladib for preventing ischemic events in stable coronary heart disease. The New England journal of medicine. 2014; 370:1702-1711. DOI: 10.1056/NEJMoa1315878 [PubMed: 24678955]

208. Nash P, Whitty A, Handwerker J, Macen J, McFadden G. Inhibitory specificity of the antiinflammatory myxoma virus serpin, SERP-1. The Journal of biological chemistry. 1998; 273:20982-20991. [PubMed: 9694848]

209. Wesley RB 2nd, Meng X, Godin D, Galis ZS. Extracellular matrix modulates macrophage functions characteristic to atheroma: collagen type I enhances acquisition of resident macrophage 
traits by human peripheral blood monocytes in vitro. Arteriosclerosis, thrombosis, and vascular biology. 1998; 18:432-440.

210. Imazio M, et al. COlchicine for the Prevention of the Post-pericardiotomy Syndrome (COPPS): a multicentre, randomized, double-blind, placebo-controlled trial. European heart journal. 2010; 31:2749-2754. DOI: 10.1093/eurheartj/ehq319 [PubMed: 20805112]

211. Bulgarelli A, Martins Dias AA, Caramelli B, Maranhao RC. Treatment with methotrexate inhibits atherogenesis in cholesterol-fed rabbits. Journal of cardiovascular pharmacology. 2012; 59:308314. DOI: 10.1097/FJC.0b013e318241c385 [PubMed: 22113347]

212. Everett BM, et al. Rationale and design of the Cardiovascular Inflammation Reduction Trial: a test of the inflammatory hypothesis of atherothrombosis. American heart journal. 2013; 166:199207 e115. DOI: 10.1016/j.ahj.2013.03.018 [PubMed: 23895801]

\section{Biographies}

Neil Ruparelia received his medical degree from University College London, UK, and obtained his DPhil from the University of Oxford, UK, after being awarded a clinical research training fellowship from the British Heart Foundation. He is a clinical cardiologist and has completed fellowships in coronary and structural intervention in Oxford, London and Milan. His principal research interests are focused on the pathogenesis of acute myocardial infarction. He is the recipient of the President's Medal in cardiology awarded by the Royal Society of Medicine, and awards from the American Heart Association and European Society of Cardiology.

Joshua T. Chai is an interventional cardiology fellow in London, UK. After graduating from Cambridge University and clinical training in London, he received his DPhil from University of Oxford on a Medical Research Council funded Clinical Research Training Fellowship. His main research interests are in atherosclerosis imaging and plaque biology. His doctoral research focused on integrated characterization of carotid atherosclerosis using novel MRI techniques, combined with plaque macrophage transcriptomic analysis utilizing laser capture microdissection. He is the recipient of a Young Investigator Award from the European Atherosclerosis Society; and a Finalist of the AHA Melvin Judkins Young Investigator Award.

Edward A. Fisher is the Leon H. Charney Professor of Cardiovascular Medicine at the NYU School of Medicine, USA, where he directs the vascular biology research programme and the Preventive Cardiology Center. He is also a visiting professor of cardiovascular medicine at the University of Oxford, following his tenure as the George Eastman Professor. Dr Fisher received his MD from NYU and a PhD from MIT for a thesis on lipoprotein metabolism. His clinical training was at the Duke and Harvard Medical Schools. His research interests include the cell biology of lipoprotein formation, the regression and imaging of atherosclerosis, and the development of nanomedicines to target plaque inflammation.

Robin P Choudhury is Professor of Cardiovascular Medicine at the University of Oxford, where he is director of the Acute Vascular Imaging Centre and an interventional cardiologist. His training was in Oxford, London, and New York. He is a Fellow of Balliol College and of the Royal College of Physicians. His interests are in the characterization of patients with atherosclerosis and vascular inflammation and in particular in the development, validation, 
and application of new approaches to vascular imaging. He is the principal investigator of the Tripartite Immunometabolism Consortium (TrIC). 


\section{Key points}

Inflammation and its failure to resolve are firmly established as central to the development and complications of several cardiovascular diseases

Targeting of inflammatory processes in experimental models has been demonstrated to be beneficial in attenuating myocardial and arterial injury, reducing disease progression, and promoting healing, but clinical translation has been disappointing

Current tools to measure 'inflammation' are nonspecific and represent downstream sequelae of biological processes, but provide little insight into disease state, site, or activation pathways

Contemporary molecular techniques (such as proteomics and gene-expression analysis) improve our ability to characterize underlying biological processes, and identify activation pathways as biomarkers and as a basis to develop new therapeutics

Noninvasive imaging tools enable the identification of activation of specific pathways and their sites, and can be used to monitor response to therapy 


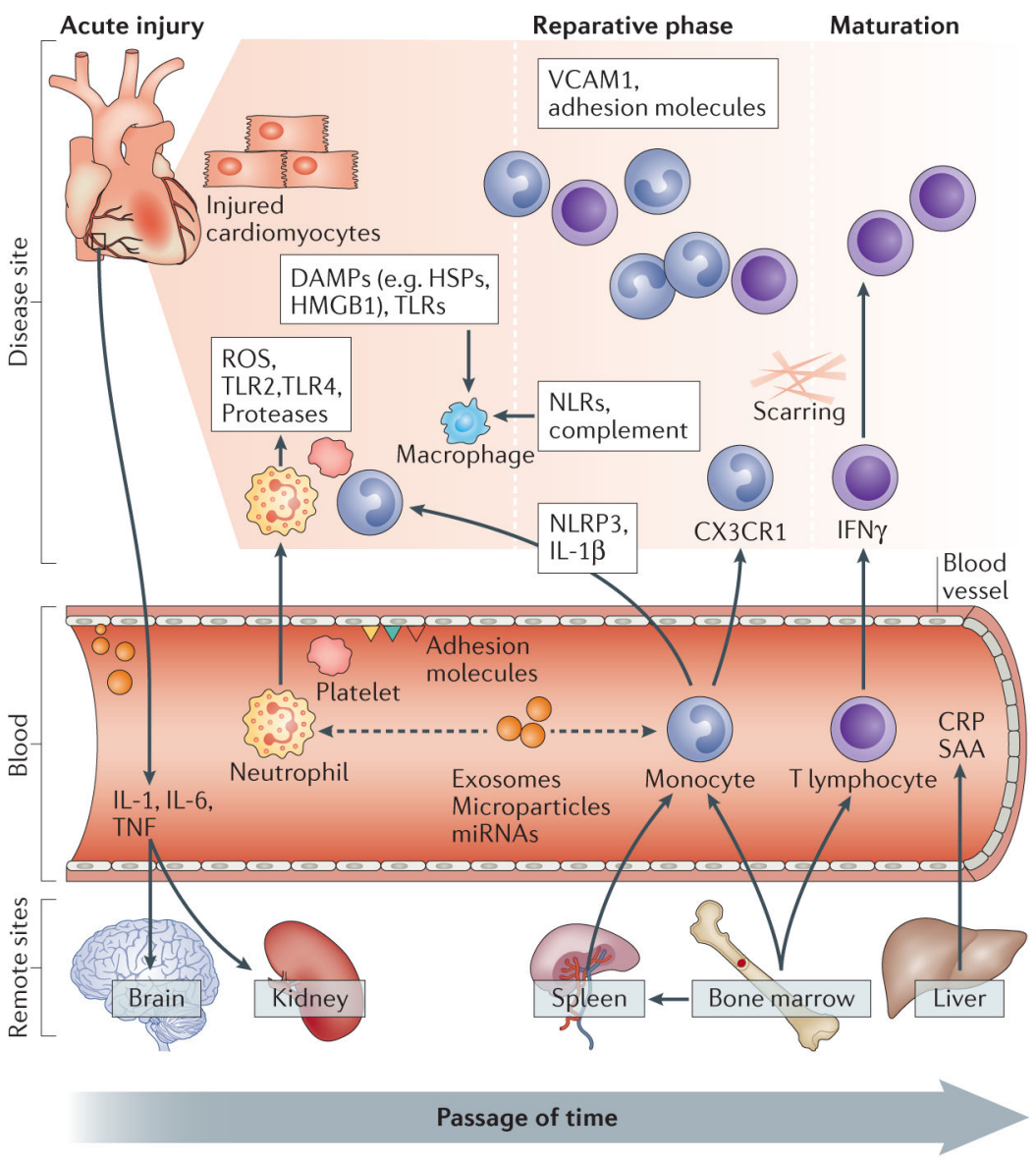

Figure 1.

Biological pathways central to the pathogenesis of acute myocardial infarction (AMI). Immediately following AMI, a number of local processes are activated with release of reactive oxygen species and cytokines with infiltration of circulating neutrophils and monocytes resulting in acute myocardial injury. Simultaneously a number of remote sites are also activated (e.g. spleen, bone marrow) via signalling pathways that result in further activation of the immune system and injury. Following this, a reparative phase ensues predominantly mediated by monocytes and T-lymphocytes resulting in tissue repair and recovery with upregulation of processes involved in angiogenesis and extracellular matrix deposition. Abbreviations: ROS: reactive oxygen species; TLR: toll-like receptors; DAMPS: damage associated molecular patterns; HSP: heat shock proteins; HMGB1: high mobility group box 1 protein; VCAM: vascular cell adhesion molecule; NLR: NOD-like receptor; NLRP3: NOD-like receptor family pyrin domain containing 3; IL: interleukin; TNF: tumour necrosis factor; IFN: interferon; CX3CR1: CX3 chemokine receptor 1; miRNA: micro ribonucleic acid; CRP: $\mathrm{C}$ reactive protein; SAA: serum amyloid A. 


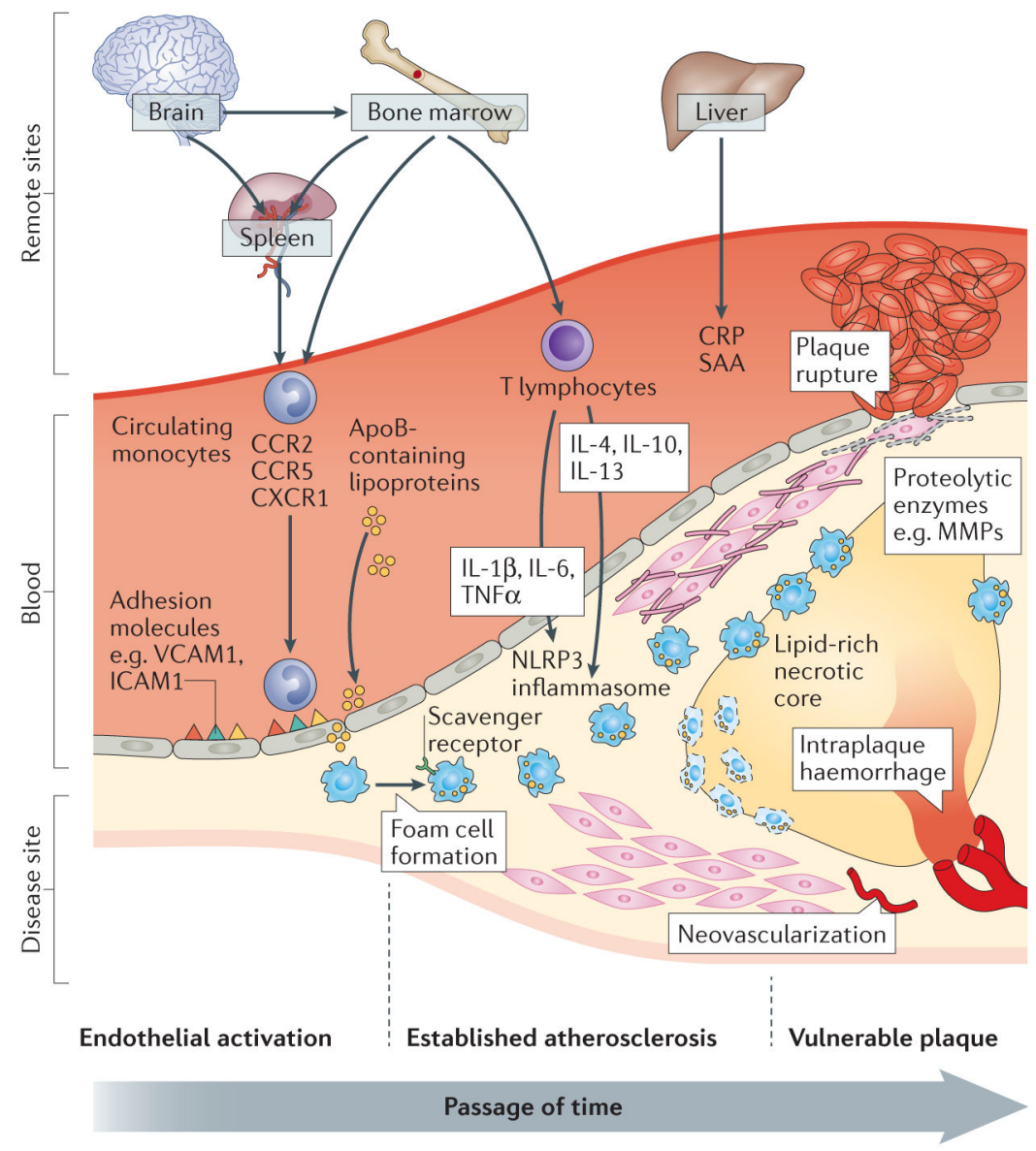

\begin{tabular}{|c|c|c|}
\hline$\{$ Macrophage & Lipid-laden foam cell & $\begin{array}{l}\text { Macrophage/foam cell that has } \\
\text { undergone necrosis or apoptosis }\end{array}$ \\
\hline$\Longleftarrow$ Collagen & Weakened collagen & $\propto$ Vascular smooth muscle cells \\
\hline
\end{tabular}

Figure 2.

Biological processes central to the pathogenesis of atherosclerosis. Endothelial cells, lymphocytes, smooth muscle cells, monocytes, and macrophages are all involved in the pathogenesis of atherosclerosis from earliest foam cell formation through to development of advanced plaques. Initial activation of the endothelium from disruptions to normal shear stress result and facilitate deposition of lipid in the subendothelial space. Endothelial activation also promotes recruitment of circulating monocytes where they terminally differentiate into macrophage or differentiate and locally proliferate into distinct functional phenotypes. Activated macrophages take up lipid and results in their transformation into macrophage-derived foam cells. As the foam cell population grows within lesions in the arterial wall, the rate of accumulation exceeds the rate of clearance, and eventually the foam cells coalesce into a lipid-rich necrotic core. Abbreviations: VCAM: vascular cell adhesion molecule; ICAM: intercellular cell adhesion molecule; CCR: chemokine-chemokine receptor; CX3CR1: CX3 chemokine receptor; IL: interleukin; TNF: tumour necrosis factor; ApoB: Apoliporotein B; CRP: C reactive protein; SAA: serum amyloid A; MMP: matrix 
metalloproteinase; NLRP3: NOD-like receptor family pyrin domain containing 3; VSMC: vascular smooth muscle cells. 


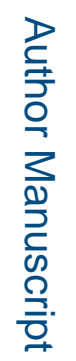

\begin{tabular}{|c|c|c|c|c|c|c|c|c|c|c|c|c|c|c|}
\hline \multirow{3}{*}{ } & 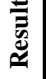 & $\mid>$ & $\overleftrightarrow{z}$ & I & I & 1 & $>$ & $\overleftrightarrow{\mathrm{z}}$ & $\mid>$ & $>$ & 1 & 1 & 1 & 1 \\
\hline & 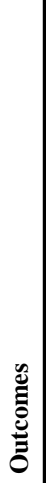 & 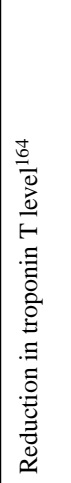 & 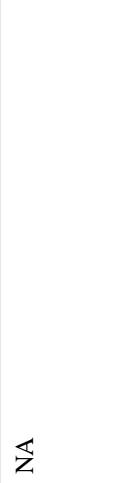 & 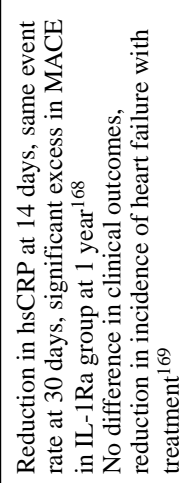 & 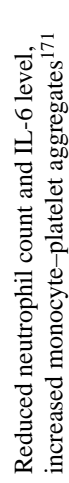 & 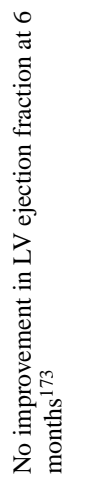 & 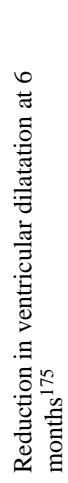 & 艺 & 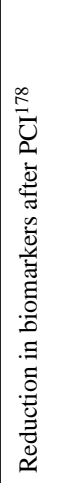 & 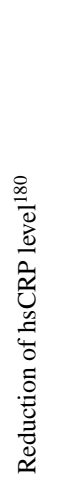 & 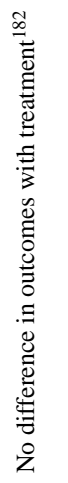 & 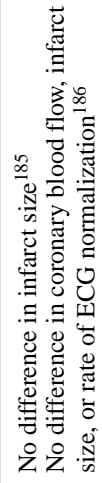 & 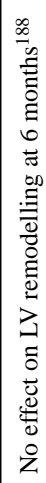 & 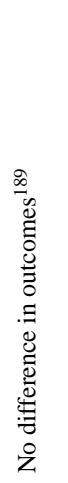 \\
\hline & 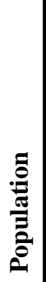 & 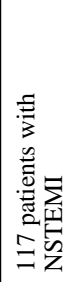 & $\overleftrightarrow{z}$ & 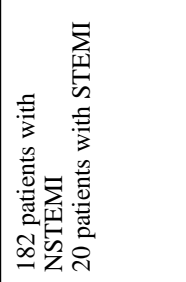 & 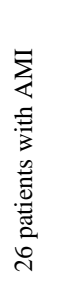 & 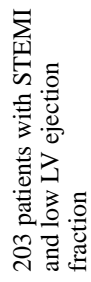 & 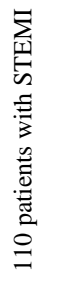 & $\overleftrightarrow{z}$ & 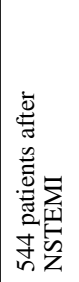 & 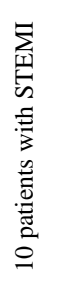 & 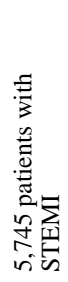 & 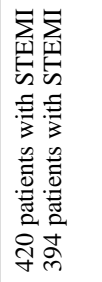 & 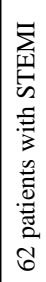 & 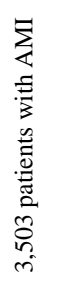 \\
\hline \multirow{3}{*}{ 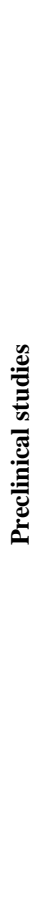 } & 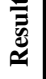 & $\mid>$ & 1 & $\mid>$ & \rangle & $>$ & $>$ & $>$ & \rangle & $\mid>$ & $>$ & \rangle & 1 & $\overleftrightarrow{z}$ \\
\hline & 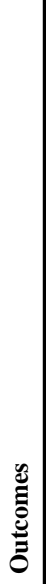 & 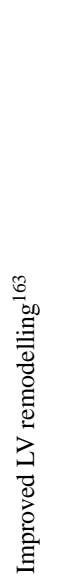 & 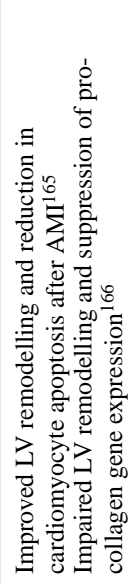 & 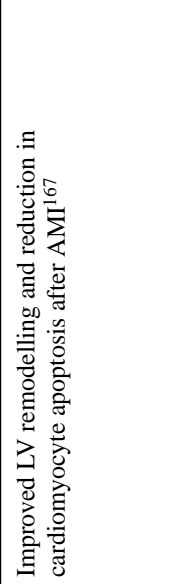 & 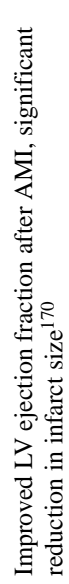 & 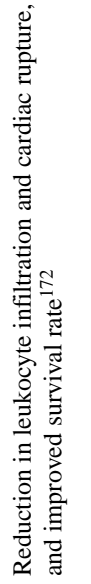 & 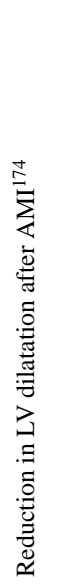 & 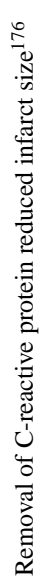 & 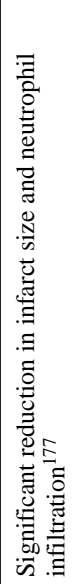 & 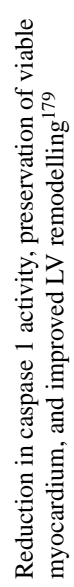 & 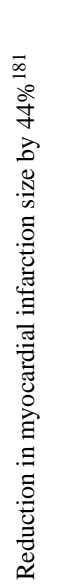 & 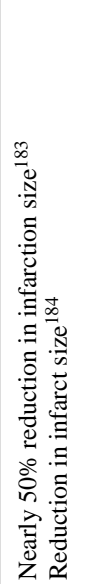 & 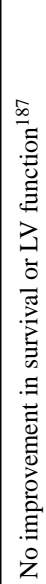 & $\overleftrightarrow{z}$ \\
\hline & 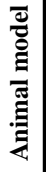 & $\stackrel{\mathscr{E}}{\Sigma}$ & $\stackrel{\circlearrowright}{\Sigma}$ & 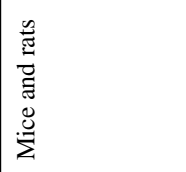 & 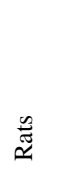 & $\underset{\Sigma}{\tilde{\Sigma}}$ & $\stackrel{\mathscr{E}}{\check{\Sigma}}$ & .00 & $\begin{array}{l}\mathscr{0} \\
\stackrel{0}{0} \\
\stackrel{0}{0}\end{array}$ & $\frac{\mathscr{8}}{\Sigma}$ & 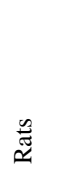 & 足. & 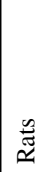 & $\overleftrightarrow{z}$ \\
\hline \multicolumn{2}{|c|}{ مِ } & 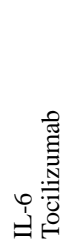 & 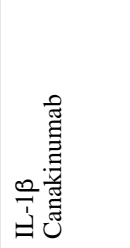 & 兄考 & 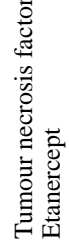 & 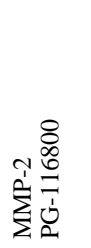 & 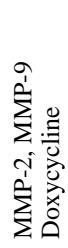 & 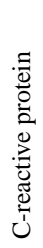 & 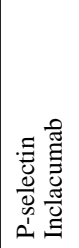 & 离 & 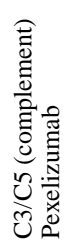 & 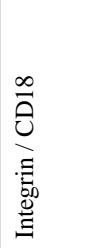 & 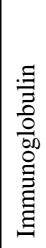 & 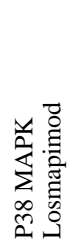 \\
\hline
\end{tabular}

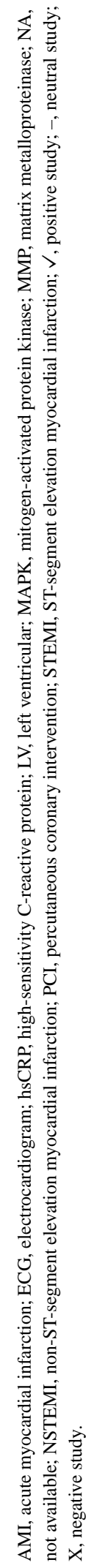

Nat Rev Cardiol. Author manuscript; available in PMC 2017 September 01. 


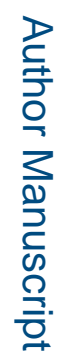

\begin{tabular}{|c|c|c|c|c|c|c|c|c|c|c|c|c|c|}
\hline \multirow{3}{*}{ 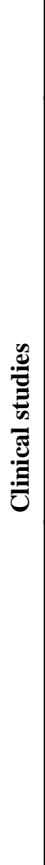 } & 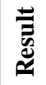 & 1 & $\underset{z}{\mathbb{z}}$ & $>$ & 1 & I & $>$ & 艺 & 1 & $\underset{z}{\mathbb{z}}$ & $x$ & I & 飞 \\
\hline & 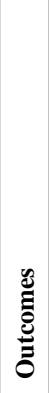 & 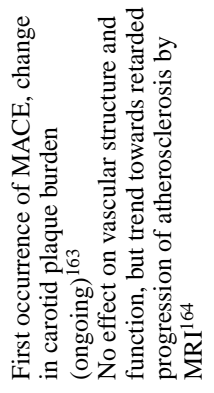 & 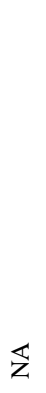 & 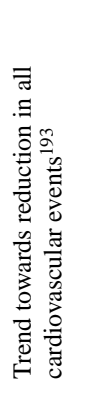 & 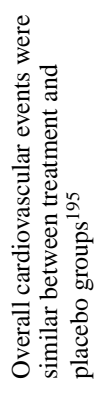 & 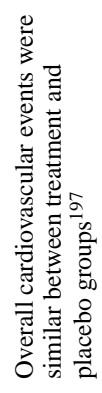 & 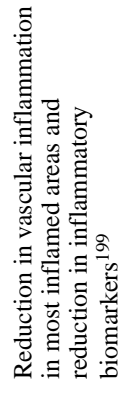 & 飞 & 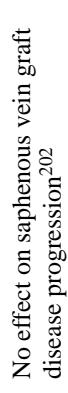 & $\overleftrightarrow{z}$ & 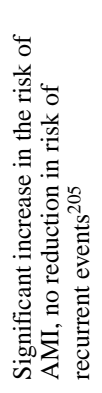 & 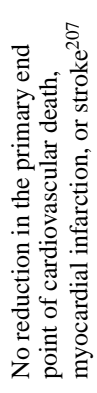 & $\mathbb{z}$ \\
\hline & 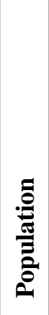 & 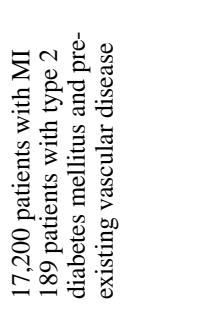 & $\overleftrightarrow{z}$ & 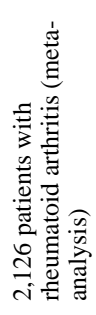 & 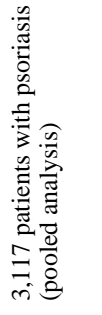 & 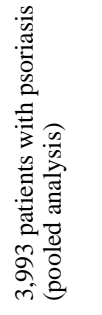 & 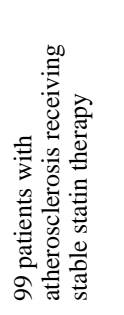 & $\overleftrightarrow{z}$ & 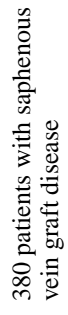 & $\mathbb{z}$ & 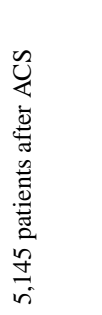 & 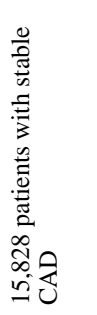 & $\overleftrightarrow{z}$ \\
\hline \multirow{3}{*}{ 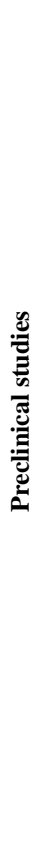 } & 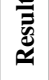 & $>$ & $>$ & $>$ & $>$ & $>$ & $>$ & $>$ & $>$ & $>$ & $>$ & $>$ & $>$ \\
\hline & 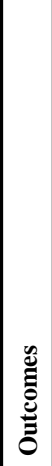 & 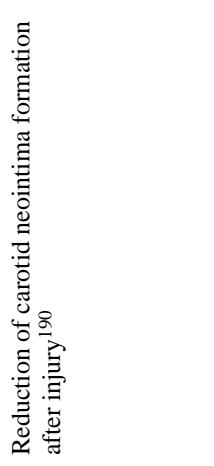 & 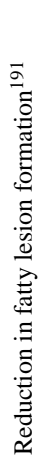 & 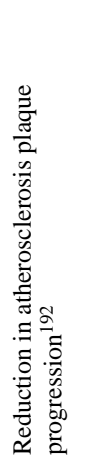 & 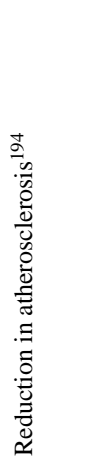 & 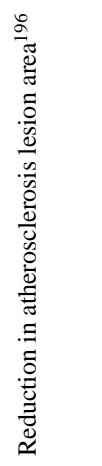 & 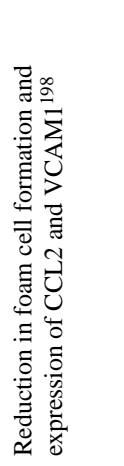 & 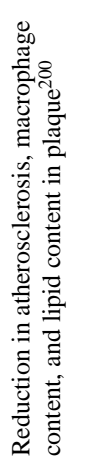 & 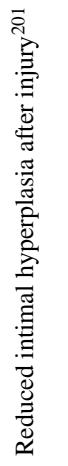 & 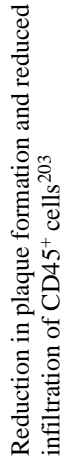 & 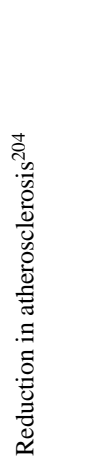 & 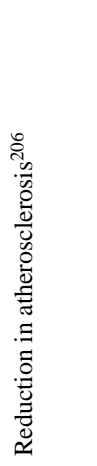 & 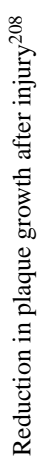 \\
\hline & 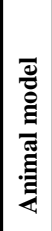 & 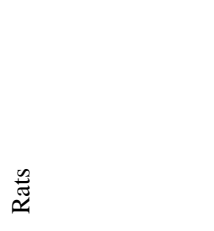 & 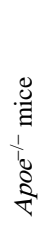 & 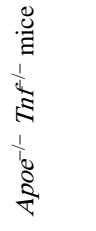 & 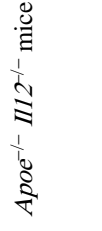 & 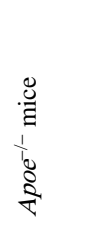 & 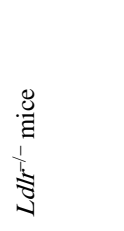 & 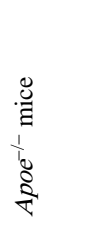 & $\begin{array}{l}\stackrel{0}{0} \\
\stackrel{0}{0} \\
\approx\end{array}$ & 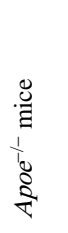 & 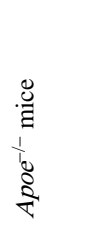 & $\stackrel{00}{0}$ & 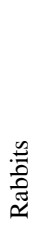 \\
\hline \multicolumn{2}{|c|}{ 岕 } & 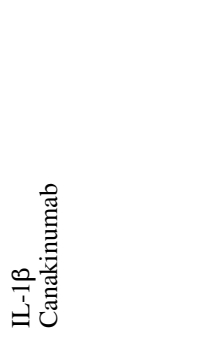 & 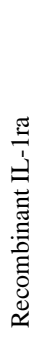 & 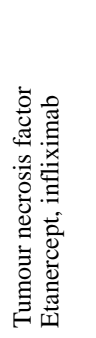 & 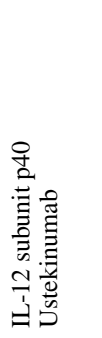 & 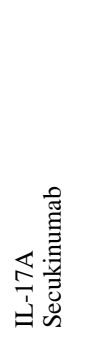 & 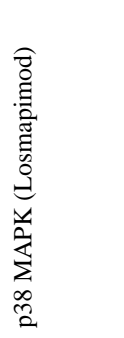 & 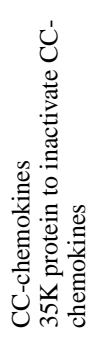 & 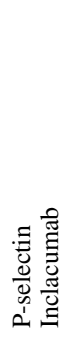 & $\sum_{\substack{j\\
}}^{\bar{s}}$ & 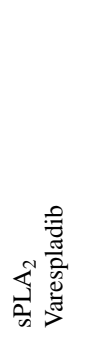 & 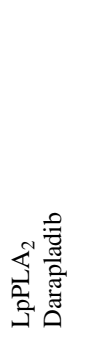 & 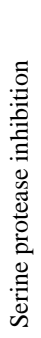 \\
\hline
\end{tabular}

Nat Rev Cardiol. Author manuscript; available in PMC 2017 September 01. 


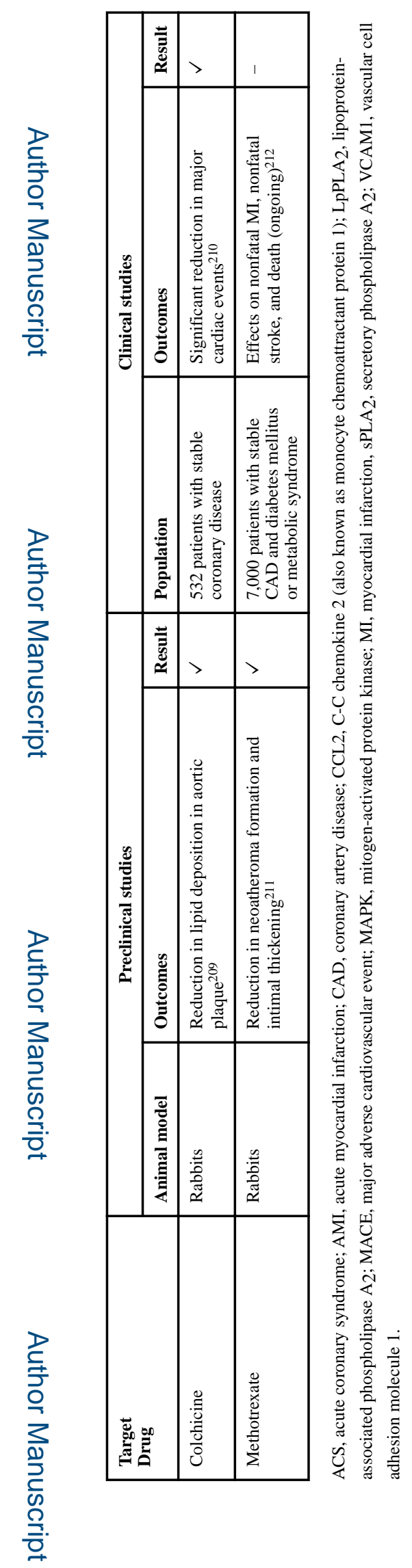

